\title{
Combined Effects of Anion Substitution and Nanoconfinement on the Ionic Conductivity of Li-Based Complex Hydrides
}

\author{
Roman Zettl, Laura de Kort, Maria Gombotz, H. Martin R. Wilkening, Petra E. de Jongh,* \\ and Peter Ngene*
}

Cite This: J. Phys. Chem. C 2020, 124, 2806-2816

Read Online

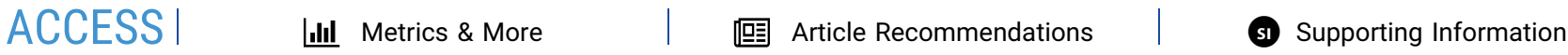

ABSTRACT: Solid-state electrolytes are crucial for the realization of safe and high capacity all-solid-state batteries. Lithium-containing complex hydrides represent a promising class of solid-state electrolytes, but they exhibit low ionic conductivities at room temperature. Ion substitution and nanoconfinement are the main strategies to overcome this challenge. Here, we report on the synthesis of nanoconfined anion-substituted complex hydrides in which the two strategies are effectively combined to achieve a profound increase in the ionic conductivities at ambient temperature. We show that the nanoconfinement of anion substituted $\mathrm{LiBH}_{4}\left(\mathrm{LiBH}_{4}-\mathrm{LiI}\right.$ and $\mathrm{LiBH}_{4}-\mathrm{LiNH}_{2}$ ) leads to an enhancement of the room temperature

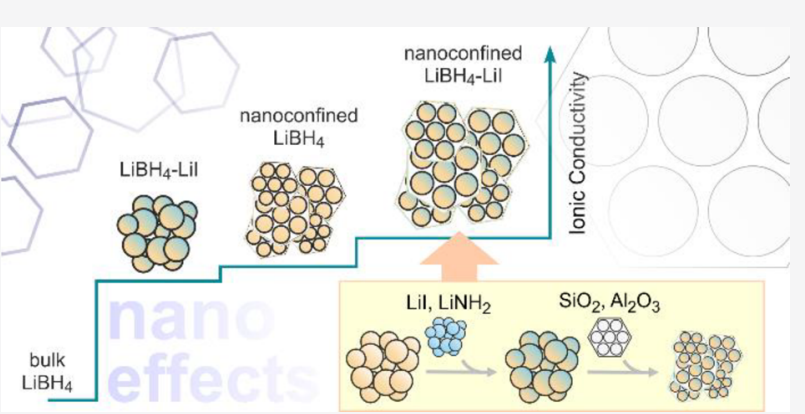
conductivity by a factor of 4 to 10 compared to nanoconfined $\mathrm{LiBH}_{4}$ and nonconfined $\mathrm{LiBH}_{4}-\mathrm{LiI}$ and $\mathrm{LiBH}_{4}-\mathrm{LiNH}_{2}$, concomitant with a lowered activation energy of $0.44 \mathrm{eV}$ for Li-ion transport. Our work demonstrates that a combination of partial ion substitution and nanoconfinement is an effective strategy to boost the ionic conductivity of complex hydrides. The strategy could be applicable to other classes of solid-state electrolytes.

\section{INTRODUCTION}

Solid-state electrolytes are indispensable for the realization of safe batteries offering high energy densities ${ }^{1,2}$ crucial for the development of both mobile applications and large-scale stationary systems that can effectively store electricity from renewable but intermittent energy sources such as solar, wind, or tidal. Current battery systems, especially those designed for electric vehicles, may suffer from flammable and volatile organic based liquid electrolytes. In many cases, this narrow electrochemical stability window of conventional aprotic electrolytes prevents the use of anode materials providing high energy densities like metallic lithium. These disadvantages have led to a renewed interest in inorganic solid-state electrolytes, because they are potentially safer than liquid electrolytes and chemically compatible with $\mathrm{Li}$ metal. In addition, if sulfur-based cathode materials are considered, they prevent the dissolution and shuttling of polysulfides, which is one of the most serious hurdles that needs to be overcome in these type of batteries that promise high energy densities. ${ }^{3}$

Various classes of materials have been investigated as solidstate ion conductors for all-solid-state batteries. ${ }^{4-8}$ These materials include garnets, ${ }^{9}$ perovskites, ${ }^{10}$ and polymers ${ }^{11}$ as well as glass type electrolytes. ${ }^{12}$ The complex metal hydrides, particularly those containing $\mathrm{Li}$ and $\mathrm{Na}$, such as $\mathrm{LiBH}_{4}$, $\mathrm{Li}_{2} \mathrm{~B}_{12} \mathrm{H}_{10}, \mathrm{NaB}_{10} \mathrm{H}_{10}$, and $\mathrm{NaCB}_{11} \mathrm{H}_{12}$ constitute a relatively new class of solid electrolytes. ${ }^{13-17}$ Due to their lightweight and high hydrogen content, these materials have been intensively investigated over the last 20 years for reversible hydrogen storage. The hydrogen could be used for fuel cells with polymer electrolyte membranes. ${ }^{18-21}$ Over a decade ago, it was shown that they also exhibit fast ionic conductivity and some also show good electrochemical stability windows up to 3 $\mathrm{V}$ versus $\mathrm{Li} / \mathrm{Li}^{+}{ }^{22-24}$

The main challenge for solid-state electrolytes in general has been the inherently low room temperature ionic conductivity, compared to liquid electrolytes. Therefore, most research effort has been focused on enhancing the ionic conductivities by structural modifications. For instance, the high ionic conductivity in complex hydrides is often a result of structural phase transition at high temperatures. A typical example is $\mathrm{LiBH}_{4}$, which exhibits an ionic conductivity of $1 \times 10^{-3} \mathrm{~S} \mathrm{~cm}^{-1}$ above $110{ }^{\circ} \mathrm{C},{ }^{14,23}$ due to the formation of the hexagonal phase, whereas at room temperature, the compound crystallizes into the orthorhombic structure, which shows poor ion conductivity. ${ }^{25-27}$

Two main approaches, which have separately been introduced in literature, have proved to be successful in boosting the room temperature ionic conductivity of solid

Received: November 12, 2019

Revised: January 14, 2020

Published: January 21, 2020 
electrolytes, especially complex hydrides. The first approach takes advantage of the partial substitution of the complex anion (e.g., $\mathrm{BH}_{4}^{-}$in $\mathrm{LiBH}_{4}$ ) by halides such as $\mathrm{Cl}^{-}$and $\mathrm{I}^{-}$or by amides. ${ }^{28-30}$ Iso- or aliovalent replacement of the $\mathrm{Li}^{+}$cations by $\mathrm{Na}^{+}, \mathrm{Ca}^{2+}$ or $\mathrm{Ce}^{3+}$ has been reported as well. ${ }^{31-33}$ Partial ion substitution is generally achieved by high-energy ball milling ${ }^{34}$ or by heating a physical mixture of the compounds at temperatures of 200 to $300{ }^{\circ} \mathrm{C}$; note that the melting point of $\mathrm{LiBH}_{4}$ is $278{ }^{\circ} \mathrm{C} .{ }^{35}$ For instance, solid solutions of $\mathrm{LiBH}_{4}-\mathrm{LiX}$ $(\mathrm{X}=\mathrm{Cl}, \mathrm{Br}, \mathrm{I})$ and $\mathrm{LiBH}_{4}-\mathrm{Li}_{3} \mathrm{~N}$ or new compounds like in $\mathrm{LiBH}_{4}-\mathrm{LiNH}_{2}$ with room temperature ionic conductivities that are much higher than the individual compounds have been reported. Several studies have been conducted to investigate the effect of heat treatment, ${ }^{36}$ the influence of LiX contents, ${ }^{35}$ and the influence of the kind of the substituting anion. ${ }^{37}$

It is generally believed that anion substitution leads to an increase in distance between neighboring $\mathrm{BH}_{4}^{-}$units which is associated with weaker Coulomb interactions in $\mathrm{LiBH}_{4}$ and hence a decrease of the transition temperature at which the compound changes from orthorhombic to hexagonal symmetry. ${ }^{38}$ Indeed, substitution with larger halide anions leads to stabilization of the hexagonal phase of $\mathrm{LiBH}_{4}$ at near ambient temperatures as clearly seen in the most investigated anion substituted complex hydride $\mathrm{LiBH}_{4}-\mathrm{LiI}^{14}{ }^{14}$ Alternatively, treatment at elevated temperatures $\left(150{ }^{\circ} \mathrm{C}\right)$ of $\mathrm{LiBH}_{4}$ together with $\mathrm{LiNH}_{2}$ leads to the formation of a new phase, $\mathrm{Li}_{2}\left(\mathrm{BH}_{4}\right)\left(\mathrm{NH}_{2}\right)$. The formation of a new phase causes a conductivity enhancement and a relatively low phase transition temperature of approximately $50{ }^{\circ} \mathrm{C} .{ }^{30,39}$ A main disadvantage of this method is, however, that the resulting compounds suffer from poor electrochemical and thermal cycling stability because of phase segregation.

The second approach, which has led to a large increase in the ionic conductivity in several classes of solid electrolytes, is interface engineering by forming nanocomposites with oxides such as $\mathrm{SiO}_{2}$ and $\mathrm{Al}_{2} \mathrm{O}_{3}{ }^{40-43}$ This approach, especially when using carbon scaffolds, was originally proposed to enhance the hydrogen sorption properties of complex hydrides, ${ }^{44-48}$ but it was additionally shown to influence the ion mobility in the materials as well. The increase in ionic conductivity is currently believed to be caused by interactions of the hydride with the scaffold surface leading to either interfacial space charge zones $^{49}$ or to the formation of highly conducting compounds at this interface ${ }^{50}$ due to changes in structure or defect density. The exact nature of the hydride/oxide interface is still a subject of intensive investigation. Alternatively, it has been shown that nanocrystalline $\mathrm{LiBH}_{4}$ has an enhanced ionic conductivity compared to the microcrystalline form. ${ }^{51}$ Interface engineering of $\mathrm{LiBH}_{4}$ is normally achieved by nanoconfinement, e.g., via melt infiltration ${ }^{52}$ of $\mathrm{LiBH}_{4}$ in the nanopores of the oxides ${ }^{40,42}$ or by ball milling ${ }^{41-43}$ a mixture of $\mathrm{LiBH}_{4}$ and the metal oxide. The two preparation methods have been reported to lead to comparable effects. Results from testing all-solid-state $\mathrm{Li}-\mathrm{S}$ batteries using $\mathrm{LiBH}_{4} / \mathrm{SiO}_{2}$ nanocomposites as electrolytes showed that this approach enhances the ionic conductivity of $\mathrm{LiBH}_{4}$ and leads to better electrochemical and cycling stability. ${ }^{53-55}$

It has been shown that in these so-called dispersed ionic conductors, only the conductor or electrolyte (e.g., $\mathrm{LiBH}_{4}$ ) near the interface with the oxide (within 1-2 nm) exhibits very high ion mobility at room temperature. ${ }^{48,55}$ Nevertheless, the volume fraction far from the interface is crucial to achieve interconnected $\mathrm{LiBH}_{4}$ particles as the silica or alumina particles do not contribute to the ionic conductivity. Only a percolating network of fast $\mathrm{Li}^{+}$diffusion pathways will guarantee facile $\mathrm{Li}$ ion transport over long distances. We hypothesize that the overall long-range ionic conductivity of the nanocomposite can be further improved if the conductive regions are interconnected via highly conductive $\mathrm{Li}^{+}$diffusion pathways rather than just bulk $\mathrm{LiBH}_{4}$.

For this purpose, we prepared nanoconfined anion substituted $\mathrm{LiBH}_{4}$. In these nanocomposites, the combined effects of partial anion substitution, either with $\mathrm{I}^{-}$or $\mathrm{NH}_{2}^{-}$, and nanoconfinement in metal oxides $\left(\mathrm{SiO}_{2}\right.$ and $\left.\mathrm{Al}_{2} \mathrm{O}_{3}\right)$ indeed leads to high room temperature Li-ion conductivities. In agreement with this observed enhancement, the activation energy for $\mathrm{Li}$ ion transport is lower than those probed for nanoconfined $\mathrm{LiBH}_{4}$ and the unconfined anion-substituted $\left(\mathrm{LiBH}_{4}-\mathrm{LiI}, \mathrm{LiBH}_{4}-\mathrm{LiNH}_{2}\right)$ systems. By using different preparation methods, we show that the enhancement seen for nanoconfined $\mathrm{LiBH}_{4}-\mathrm{LiI}$ and $\mathrm{LiBH}_{4}-\mathrm{LiNH}_{2}$ is indeed due to the combined effects of interfacial interactions with the metal oxide surface groups and the presence of highly conducting anion-substituted $\mathrm{LiBH}_{4}$ located further away from the $\mathrm{SiO}_{2}$ or $\mathrm{Al}_{2} \mathrm{O}_{3}$ surfaces. $\mathrm{LiBH}_{4}$ was used as an excellent model system to demonstrate the effect of combining anion substitution and nanoconfinement, and we believe that this approach and outcome are applicable to a wide variety of solid-state electrolytes.

\section{EXPERIMENTAL SECTION}

Synthesis of Silica Supports. MCM-41 was synthesized using the procedure described by Cheng et al. ${ }^{56}$ In brief, hexadecyltrimethylammonium bromide (Sigma-Aldrich, $\geq 96.0 \%$ ) and tetramethylammonium hydroxide solution (Sigma-Aldrich, 25 wt \% in $\mathrm{H}_{2} \mathrm{O}$ ) were mixed with deionized water. After the addition of the silica source (Aerosil 380), the white suspension was stirred for $2 \mathrm{~h}$ at $30{ }^{\circ} \mathrm{C}$ and kept at this temperature for another $24 \mathrm{~h}$ unstirred in a closed polypropylene bottle. The composition of the mixture was $1.00 \mathrm{SiO}_{2}$ : 0.19 (TMA)OH: 0.27 (CTA)Br: $40 \mathrm{H}_{2} \mathrm{O}$. The jelly like product was heated to $140{ }^{\circ} \mathrm{C}$ in stainless steel autoclaves and kept there for $48 \mathrm{~h}$. After being naturally cooled to room temperature, the mixture was thoroughly washed, filtered, and dried at $120{ }^{\circ} \mathrm{C}$ for approximately $12 \mathrm{~h}$. The final calcination step $\left(550^{\circ} \mathrm{C}, 12 \mathrm{~h}\right)$ was carried out after heating the sample first to $100{ }^{\circ} \mathrm{C}$ for $1 \mathrm{~h}$ as an additional drying step.

SBA-15 was prepared according to Zhao et al. ${ }^{57}$ Poly(ethylene glycol)-block-poly(propylene glycol)-block-poly(ethylene glycol) (Sigma-Aldrich, PEG-PPG-PEG, Pluronic, P-123), hydrochloric acid fuming 37\% (Merck, for analysis), and deionized water were stirred at $35{ }^{\circ} \mathrm{C}$. Tetraethyl orthosilicate (Sigma-Aldrich, $\geq 99.0 \%$ GC, TEOS) was added dropwise to the solution, and the solution was then stirred for $24 \mathrm{~h}$ at $40{ }^{\circ} \mathrm{C}$ resulting in a composition of 0.015 P123:5.2 $\mathrm{HCl}: 129 \mathrm{H}_{2} \mathrm{O}: 1 \mathrm{TEOS}$. This mixture was kept at $100{ }^{\circ} \mathrm{C}$ in a closed polypropylene bottle for $48 \mathrm{~h}$, followed by extensive washing and filtration. Subsequently, the product was predried $\left(60{ }^{\circ} \mathrm{C}, 24 \mathrm{~h}\right.$, air $)$, dried $\left(120^{\circ} \mathrm{C}, 8 \mathrm{~h}\right.$, air $)$, and calcined $(1.2$ ${ }^{\circ} \mathrm{C} \min ^{-1}, 550{ }^{\circ} \mathrm{C}, 6 \mathrm{~h}$, air $)$.

Electrolyte Preparation. Alumina $\left(\mathrm{Al}_{2} \mathrm{O}_{3}\right)$ was purchased from Sasol (product brand Puralox SCCa-5/200), while lithium amide ( $95 \%$ pure), lithium iodide ( $98 \%$ pure), and lithium borohydride (95\% pure) were purchased from SigmaAldrich. The metal oxide supports (MCM-41, SBA-15 and $\mathrm{Al}_{2} \mathrm{O}_{3}$ ) were first dried under a vacuum at $220{ }^{\circ} \mathrm{C}$ overnight; 
then we stored them in an Ar purified glovebox (MBraunLabmaster, typically $\mathrm{H}_{2} \mathrm{O}$ and $\mathrm{O}_{2}<1 \mathrm{ppm}$ ). All subsequent sample handling and transfer were carried out in the glovebox to avoid contamination with air or traces of moisture. The $\mathrm{LiBH}_{4}-\mathrm{LiI} /$ oxide nanocomposites were prepared using two different methods. In the first method, $\mathrm{LiBH}_{4}$ and $\mathrm{LiI}$ were physically mixed in molar ratios of $10,20,30$, and $40 \mathrm{~mol} \%$ LiI with respect to $\mathrm{LiBH}_{4}$. Subsequently, the materials were mixed with the desired amount of the oxide and placed in a quartz reactor which was then inserted inside a stainless-steel high-pressure autoclave (Parr). The amounts were calculated in order to fill the oxide pores by $130 \%$, meaning that all pores were filled and voids between particles and space between grains were filled additionally. Melt infiltration was carried out at 50 bar $\mathrm{H}_{2}$ pressure and a temperature of $295{ }^{\circ} \mathrm{C}$ for $30 \mathrm{~min}$; the heating rate was approximately $3{ }^{\circ} \mathrm{C} \mathrm{min}{ }^{-1} \cdot{ }^{48}$ During this process, LiI$\mathrm{LiBH}_{4}$ forms a solid solution $\left((1-x) \mathrm{LiBH}_{4}-x \mathrm{LiI}\right.$ with $x=0.1$, $0.2,0.3,0.4)$ which melts and infiltrates the pores of the oxide. Upon cooling, the molten solid solution solidifies in the pores of the support material, and the excess amount remains at the external surface of the support.

In the second approach, the samples were prepared by combing solution impregnation and melt infiltration. A solution of LiI and water or ethanol was prepared. The desired amount of the solution was added dropwise, using a syringe and a septum, to the metal oxide support contained in a roundbottom flask. This was done outside the glovebox but by using a Schlenk line to avoid contamination. The impregnated oxide was kept at room temperature for $3 \mathrm{~h}$, after which the solvent was removed. Subsequently, the mixture was dried at $250{ }^{\circ} \mathrm{C}$ overnight under a dynamic vacuum. In order to reach the desired amount of $\mathrm{LiI}$ in the pores, the procedure was repeated twice. The $\mathrm{LiI} /$ metal oxide nanocomposite was mixed with $\mathrm{LiBH}_{4}$ to reach a molar ratio $\mathrm{LiI} / \mathrm{LiBH}_{4}$ of $20: 80$ with the volume of $\mathrm{LiBH}_{4}-\mathrm{LiI}$ corresponding to $130 \%$ of the total pore volume of the silica (or alumina). The mixture was then inserted into a sample holder placed inside a stainless-steel high-pressure autoclave, pressurized to $50 \mathrm{bar} \mathrm{H}_{2}$ and heated at $3{ }^{\circ} \mathrm{C} \mathrm{min}^{-1}$ to $295{ }^{\circ} \mathrm{C}$. The dwell time was $30 \mathrm{~min}$. The molten $\mathrm{LiBH}_{4}$ infiltrates the oxide pores and reacts with the nanoconfined $\mathrm{LiI}$ to form $\mathrm{LiBH}_{4}-\mathrm{LiI}$.

Reference samples of $\mathrm{LiBH}_{4}-\mathrm{LiI}$ solid solutions and nanoconfined $\mathrm{LiBH}_{4}$ were prepared under the same autoclave conditions as outlined above. Solid solutions were synthesized by heating mixtures of $\mathrm{LiBH}_{4}$ and $\mathrm{LiI}$ without adding the metal oxide support; nanoconfined $\mathrm{LiBH}_{4}$ was obtained without adding LiI to the mixture. A third reference sample was bulk $\mathrm{LiBH}_{4}$, which was ground and melted under the same autoclave conditions and recrystallized.

$\mathrm{LiBH}_{4}-\mathrm{LiNH}_{2}$ /oxide nanocomposites were prepared using a two-step preparation method. First, $\mathrm{LiBH}_{4}$ and $\mathrm{LiNH}_{2}$ were physically mixed in a molar ratio of $50 \% \mathrm{LiNH}_{2}$ with respect to $\mathrm{LiBH}_{4}$. Afterward, the physical mixture was placed in a stainless-steel reactor which was then inserted into a stainlesssteel high-pressure autoclave. The solid-state reaction was carried out at 50 bar $\mathrm{H}_{2}$ pressure and at $150{ }^{\circ} \mathrm{C}$ (heating rate $2.5{ }^{\circ} \mathrm{C} \mathrm{min}{ }^{-1}$ ) for $30 \mathrm{~min}$ to form a solid solution with the composition $0.5 \mathrm{LiBH}_{4}-0.5 \mathrm{LiNH}_{2}$. Subsequently, the solid solution was mixed with the desired amount of oxide in order to fill the pores by $130 \%$. Melt infiltration was carried out at $50 \mathrm{bar} \mathrm{H}_{2}$ pressure at $120{ }^{\circ} \mathrm{C}\left(2.5^{\circ} \mathrm{C} \mathrm{min}-1\right)$ for $30 \mathrm{~min}$. Upon cooling, the molten solid solution recrystallized in the pores of the support material to form nanoconfined $\mathrm{LiBH}_{4}-$ $\mathrm{LiNH}_{2}$.

Characterization of Pristine Materials and Composites. X-ray diffraction was performed with a Bruker-AXS D-8 Advance X-ray diffractometer with Co $\mathrm{K} \alpha \alpha_{1,2}$ radiation $(\lambda=$ $1.79026 \AA)$. The samples were placed in an airtight sample holder, and diffractograms were recorded at room temperature covering a $2 \theta$ range of $10^{\circ}$ to $100^{\circ}$ for alumina-based samples and of 20 to $80^{\circ} 2 \theta$ for the silica containing samples as well as the crystalline samples. The increment and scan duration per point was $0.12^{\circ} 2 \theta$ and $4 \mathrm{~s}$, respectively, for the alumina samples; $0.06^{\circ} 2 \theta$ and $2 \mathrm{~s}$, respectively, for the silica samples; and $0.03^{\circ} 2 \theta$ and $1 \mathrm{~s}$, respectively, for the crystalline samples. Rietveld refinement was carried out using the software X'PertHighScore Plus. A Le-Bail fit was applied to analyze the pattern; literature patterns of hexagonal $\mathrm{LiBH}_{4}$ taken from the Inorganic Crystal Structure Database served as reference. To refine the patterns, we used the lattice parameters of hexagonal $\mathrm{LiBH}_{4}$ as starting values $(a=4.28 \AA$, $b=4.28 \AA$, $c=$ $6.98 \AA)$.

Diffuse reflectance infrared Fourier transform spectra (DRIFTS) were obtained by a PerkinElmer 2000 spectrometer and a MCT detector. Sixteen scans were accumulated with a resolution of $4 \mathrm{~cm}^{-1}$ in the range of 500 to $4500 \mathrm{~cm}^{-1}$. An airtight sample holder ( $\mathrm{KBr}$ background) guaranteed no air contamination during the measurements. Data acquisition was realized by recording absorbance versus wavenumber. The absorbance is directly converted to K-M units, introduced by Kubleka and Munk, which includes a scattering component and is, therefore, typically used for the analysis of powder samples.

Conductivity Measurement. Alternating current (AC) impedance spectroscopy measurements were performed using a Princeton Applied Research Parstat 2273. Lithium foil (Sigma-Aldrich, 99.9\%, $0.38 \mathrm{~mm}$ thick and $12 \mathrm{~mm}$ in diameter leading to a surface of $1.33 \mathrm{~cm}^{2}$ ) was firmly placed on top of two $13 \mathrm{~mm}$ stainless steel dies. A $100-300 \mathrm{mg}$ portion of the electrolyte was placed between the two lithium foils in a standard pellet die set. The sample was pressed using a pressure of 2 tons, resulting in a final electrolyte thickness of 1 to $2 \mathrm{~mm}$, excluding the $\mathrm{Li}$ foil. With the weight of the samples, we calculated that the void fraction of the pellets is below $20 \%$. The pressed sample pellet, which is tightly connected to the $\mathrm{Li}$ foils and stainless-steel dies, was placed in a custom-made impedance cell housed in a Büchi B-585 glass oven that was placed in an Ar-filled glovebox. The voltage amplitude of the AC signal was $1 \mathrm{~V}$; we measured complex impedances over a frequency range from $1 \mathrm{MHz}$ to $1 \mathrm{~Hz}$. Generally, the pellets were heated from room temperature to 50 or $130{ }^{\circ} \mathrm{C}$ (depending on the sample), and then the samples were cooled down to room temperature. During this temperature cycle, impedance scans were acquired in steps of 5 or $10^{\circ} \mathrm{C}$. Before the acquisition of each scan, the measurement cell was allowed to equilibrate at the desired temperature for $45 \mathrm{~min}$ (while heating), $90 \mathrm{~min}$ (while cooling), and $150 \mathrm{~min}$ (for measurements at room temperature). The entire sequence was repeated for 2 to 3 cycles to investigate any hysteresis behavior and to detect any changes of the samples. Matlab and ZView software were used to fit the raw data by using Nyquist plots. A constant phase element (CPE) and a resistor connected in parallel were used as appropriate equivalent circuit to parametrize the data. Capacitances, $C$, were calculated according to $C=R^{(1-n) / n} \times Q^{1 / n} . R$ is the resistance 
in $\Omega$, i.e., it denotes the real part of the complex impedance; $Q$ has the numerical value of the admittance at $\omega=1 \mathrm{rad} \mathrm{s}^{-1} \cdot n$ is a dimensionless variable characterizing the deviation of the CPE from the behavior of an ideal RC unit, which would yield $n=1$.

NMR Line Shape Measurement. To underpin the findings by conductivity spectroscopy, we recorded ${ }^{7} \mathrm{Li}$ (spin$3 / 2$ ) nuclear magnetic resonance (NMR) spectra at a magnetic field of $7 \mathrm{~T}$, corresponding to a Larmor frequency of $116 \mathrm{MHz}$, by employing a Bruker Advance III solid-state spectrometer. We used a standard broadband probe to acquire variabletemperature NMR spectra with a one pulse sequence under static, i.e., nonrotating conditions. The $\pi / 2$ pulse length slightly depended on temperature and ranged from 2.1 to 2.3 $\mu$ s. Such short pulse lengths ensured nonselective excitation of the whole spectra. Up to 16 scans were accumulated to form an average free induction decay, which, after Fourier transformation, yield the ${ }^{7} \mathrm{Li}$ NMR spectra. The temperature in the sample chamber was monitored by a Eurotherm controller. Temperature adjustment was achieved, with an accuracy of $\pm 2 \mathrm{~K}$, with a heater that was constantly flushed with a stream of dry nitrogen gas.

\section{RESULTS AND DISCUSSION}

Structure of $\left((1-x) \mathrm{LiBH}_{4}-x \mathrm{Lil}\right.$ and Its Nanoconfined Counterpart As Seen by XRD and DRIFTS. First, we discuss the structural properties of (i) the $\mathrm{LiBH}_{4}-\mathrm{LiI}$ solid solutions $\left((1-x) \mathrm{LiBH}_{4}-x \mathrm{LiI}\right)$ containing 10 to $40 \mathrm{~mol} \% \mathrm{I}(x=$ $0.1,0.2,0.3$ and 0.4 ) and (ii) the nanocomposites with different oxides viz. $\gamma-\mathrm{Al}_{2} \mathrm{O}_{3}, \mathrm{SBA}-15$, and MCM-41. The compositions of the samples in wt \% are given in Table S1. Structural details of the hydrides, oxides, and nanocomposite materials are shown in Figure 1 as well as in Table S2 and Figures $\mathrm{S} 1$ to $\mathrm{S} 6$. Figure 1 shows the XRD powder pattern of a $20 \mathrm{~mol} \% \mathrm{LiI}_{-} \mathrm{LiBH}_{4}$ solid solution and the patterns of the nanocomposites prepared using two different routes, i.e., comelt infiltration and impregnation with LiI followed by melt infiltration with $\mathrm{LiBH}_{4}$. For comparison, the XRD pattern of $\mathrm{LiI}$ and the patterns of orthorhombic and hexagonal $\mathrm{LiBH}_{4}$ are also included. The influence of LiI on the on XRD patterns of the solid solutions and the composites is illustrated in Figures S7 and S8. The patterns shown here are normalized to the highest intensities; $h k l$ values are added to distinct reflections of $\mathrm{LiBH}_{4}{ }^{58,59}$ and $\mathrm{LiI},{ }^{60-62}$ respectively. The XRD patterns of the $\mathrm{LiBH}_{4}-\mathrm{LiI}$ samples with 10 and $20 \mathrm{~mol} \%$ LiI (Figure S7) clearly differ from those of orthorhombic $\mathrm{LiBH}_{4}$ and LiI. Instead they resemble the pattern of hexagonal $\mathrm{LiBH}_{4}$ being the stable phase at elevated temperatures. The reflections in the range from $27^{\circ}$ to $32^{\circ} 2 \theta$ are shifted toward lower $2 \theta$ values by approximately $1^{\circ} 2 \theta$. This shift reveals successful incorporation of $\mathrm{LiI}$ and is caused by lattice expansion because $\mathrm{I}^{-}$is larger than $\mathrm{BH}_{4}{ }^{-35} \mathrm{~A}$ similar shift has been reported in literature. ${ }^{14}$ Rietveld refinement of the diffraction data for the $0.8 \mathrm{LiBH}_{4}-0.2 \mathrm{LiI}$ solid solution yielded an hcp unit cell with the following lattice parameters $a=4.44 \AA, b=4.44 \AA$, and $c=$ 7.19 A. Simultaneously with lattice expansion, the density increased from $0.67 \mathrm{~g} / \mathrm{cm}^{3}$ for bulk $\mathrm{LiBH}_{4}$ to $1.20 \mathrm{~g} / \mathrm{cm}^{3}$ for $0.8 \mathrm{LiBH}_{4}-0.2 \mathrm{LiI}$. Samples with more than $20 \mathrm{~mol} \% \mathrm{LiI}$ revealed reflections of pure LiI indicating a solubility limit for the $\mathrm{LiBH}_{4}-\mathrm{LiI}$ system (Figure S7).

Confinement of the $\mathrm{LiBH}_{4}-\mathrm{LiI}$ solid solutions in the oxide nanopores led to both broadening and a decrease in intensity of the diffraction peaks (see Figures 1 and S8). Peak

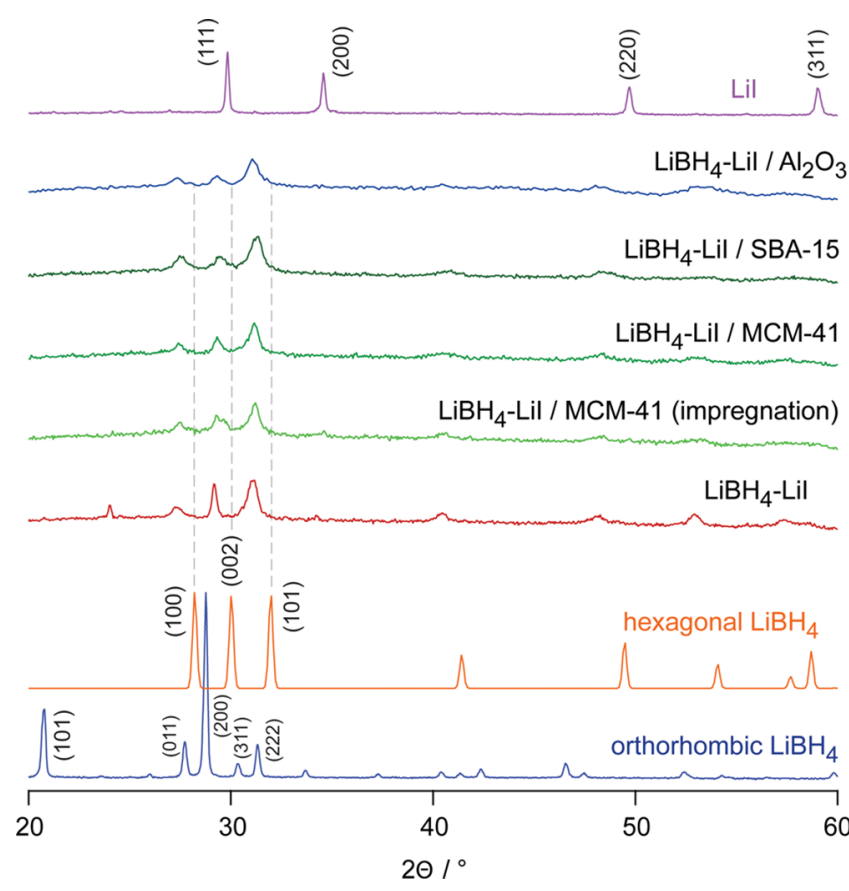

Figure 1. $\mathrm{XRD}$ powder patterns of the various $\mathrm{LiBH}_{4}-\mathrm{LiI} /$ oxide nanocomposites investigated. For comparison, the positions of the reflection of $\mathrm{LiBH}_{4}$ in its hexagonal form are included as well. In addition, the pattern of $\mathrm{LiBH}_{4}-\mathrm{LiI}(20 \mathrm{~mol} \%$ of $\mathrm{LiI})$ and $\mathrm{LiI}$ are also shown. Values in brackets refer to $h k l$ indices. The shift of the reflections toward lower diffraction angles indicates successful incorporation of $\mathrm{LiI}$ that stabilizes the hexagonal form of $\mathrm{LiBH}_{4}$.

broadening is expected because of size effects and lattice strain, whereas the decrease in intensity suggests a decrease in the long-range order. Note, however, that the composites shown here contain $30 \mathrm{vol} \%$ more $\mathrm{LiBH}_{4}-\mathrm{LiI}$ than is required to fill all the pores of the scaffold. This is essential for interconnectivity between the $\mathrm{LiBH}_{4}$ particles. For the nanocomposites with $\mathrm{LiBH}_{4}-\mathrm{LiI} \leq 100 \%$ of the total pore volume of the scaffold, no crystalline phase was observed. Thus, we conclude that nanoconfinement led to a significant decrease in crystallinity of the samples. The similarity in the diffraction patterns of the nanocomposites prepared using the different methods (Figure 1) suggests that both methods are useful for the preparation of $\mathrm{LiBH}_{4}-\mathrm{LiI} /$ metal oxide solutions. Moreover, the use of different oxide supports did not lead to major differences in the XRD patterns of the nanocomposites.

Further evidence for successful incorporation of the solid solutions into the oxide pores is provided by nitrogen physisorption measurements. The measurements showed that only a negligible amount of nitrogen was adsorbed by the nanocomposites. This finding proved that the pores were occupied by the electrolyte $\mathrm{LiBH}_{4}-\mathrm{LiI}$.

DRIFTS was used to investigate the nature of chemical bonding in the different samples prepared. In Figure 2 the spectrum of the $\mathrm{LiBH}_{4}-\mathrm{LiI} / \mathrm{Al}_{2} \mathrm{O}_{3}$ nanocomposite is compared to spectra of bulk $\mathrm{LiBH}_{4}, \mathrm{LiBH}_{4}-\mathrm{LiI}$, and pristine $\mathrm{Al}_{2} \mathrm{O}_{3}$. The spectra are presented in arbitrary K-M units (for further explanation see the Experimental Section). Macrocrystalline, that is, bulk $\mathrm{LiBH}_{4}$, shows characteristic bands between 1000 and $1500 \mathrm{~cm}^{-1}$ which correspond to $\left[\mathrm{BH}_{4}\right]^{-}$bending vibrations; bands appearing in the range from 2000 to 2800 $\mathrm{cm}^{-1}$ can be associated with stretching vibrations in $\left[\mathrm{BH}_{4}\right]^{-63,64}$ The most preeminent bands of $\mathrm{LiBH}_{4}$ are marked 


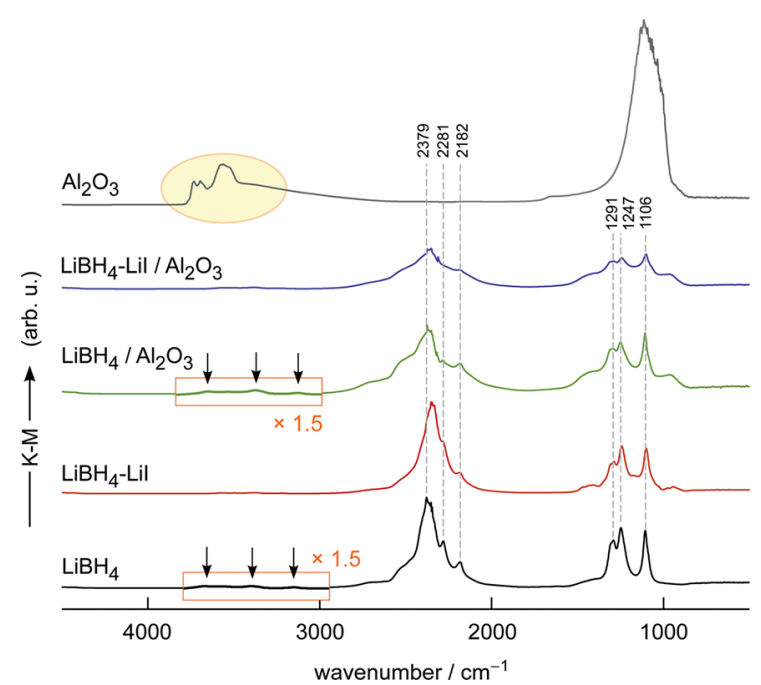

Figure 2. DRIFT spectra of $\mathrm{Al}_{2} \mathrm{O}_{3}$, nanoconfined $\mathrm{LiBH}_{4}-\mathrm{LiI} / \mathrm{Al}_{2} \mathrm{O}_{3}$, nanoconfined $\mathrm{LiBH}_{4} / \mathrm{Al}_{2} \mathrm{O}_{3}$, and $\mathrm{LiBH}_{4}-\mathrm{LiI}(20 \mathrm{~mol} \%$ of $\mathrm{LiI})$. For comparison, the spectrum of $\mathrm{LiBH}_{4}$ is also shown. Main peaks are marked by vertically drawn dashed lines with the wavenumbers indicated. K-M intensities (see the ordinate axis) are in arbitrary units. See text for further explanation.

with dashed lines in gray color; the corresponding wavenumbers are indicated. The spectrum of the $\mathrm{LiBH}_{4}-\mathrm{LiI}$ solution resembles that of $\mathrm{LiBH}_{4}$, the band characterizing the stretching vibrations $\left(2379 \mathrm{~cm}^{-1}\right)$ is, however, slightly shifted toward a lower wavenumber. Most likely, this shift is due to the effect of negative chemical pressure resulting from an increased unit cell by addition of I, as previously observed for halidesubstituted $\mathrm{BH}_{4}{ }^{65}$ Also, a stronger electronic interaction between iodine and $\mathrm{Li}$, because of the higher electronegativity of the halides compared to $\mathrm{BH}_{4}{ }^{-}$, can lead to such a change in vibration frequencies. ${ }^{66}$ For $\mathrm{LiBH}_{4}-\mathrm{LiI} / \mathrm{Al}_{2} \mathrm{O}_{3}$, the bands are clearly broadened due to nanoconfinement. A similar broadening effect is also observed for $\mathrm{LiBH}_{4} / \mathrm{Al}_{2} \mathrm{O}_{3}$. It suggests that the structure of the confined materials is different from the bulk compound. This observation is in line with previous studies on nanoconfined $\mathrm{LiBH}_{4}{ }^{67-69}$

Interestingly, the bands of $\mathrm{Al}_{2} \mathrm{O}_{3}$ in the region from 3400 to $3800 \mathrm{~cm}^{-1}$, representing $\mathrm{OH}$ surface groups, ${ }^{70}$ almost disappear after the pores are filled with electrolyte; see the vertical arrows in Figure 2. The same behavior is found for the characteristic vibrations of the surface $\mathrm{OH}$-silanol groups of silica ${ }^{71,72}$ in the samples $\mathrm{LiBH}_{4} / \mathrm{SiO}_{2}, \mathrm{LiI} / \mathrm{SiO}_{2}$, and $\mathrm{LiBH}_{4}-$ $\mathrm{LiI} / \mathrm{SiO}_{2}$ (see Figures S9 and S10). Interaction of $\mathrm{LiBH}_{4}$ with the surface is the origin of the high ionic conductivity of $\mathrm{LiBH}_{4}$ /oxide nanocomposites.

Ionic Conductivity of Nanoconfined $\mathrm{LiBH}_{4}-\mathrm{Lil}$. To evaluate the effects of different $\mathrm{LiI}$ concentrations on ionic conductivity, we recorded complex impedance data at different temperatures and analyzed the results in the Nyquist representation; see Figure 3. An overview of results from impedance spectroscopy of the $\mathrm{LiBH}_{4}-\mathrm{LiI}$ solid solutions and the nanocomposites is given in Table S3 and Figure S11. The overall ionic conductivity of the confined and pure solid solutions increased with increasing amounts of added LiI. At LiI contents higher than $20 \mathrm{~mol} \%$, the conductivity started to decrease (Figure S12). This is in line with results from XRD pointing to crystalline (unreacted) LiI above this composi- a)
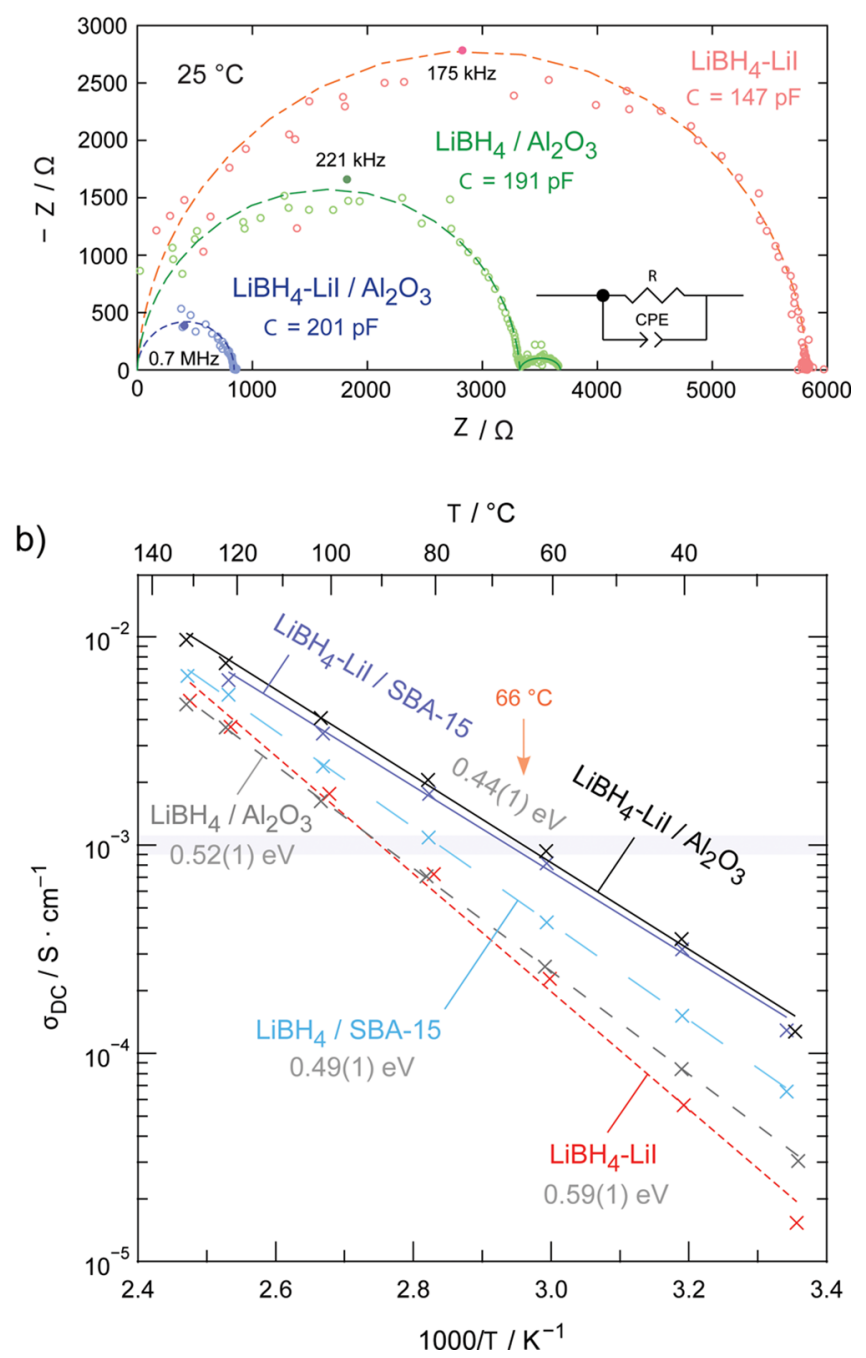

Figure 3. (a) Nyquist plots, that is, the imaginary part, $-Z^{\prime \prime}$, of the complex impedance plotted versus the real part $Z^{\prime}$, of nanoconfined $\mathrm{LiBH}_{4}-\mathrm{LiI} / \mathrm{Al}_{2} \mathrm{O}_{3}$ and $\mathrm{LiBH}_{4} / \mathrm{Al}_{2} \mathrm{O}_{3}$. The $\mathrm{LiBH}_{4}-\mathrm{LiI}$ sample $(20 \mathrm{~mol}$ $\% \mathrm{LiI})$ is also shown. Values in $\mathrm{pF}$ show the capacitances obtained after parametrizing the main (nondepressed) semicircles with the equivalent circuit shown; see also Experimental section. The line approximating the second semicircle of the curve belonging to $\mathrm{LiBH}_{4}$ / $\mathrm{Al}_{2} \mathrm{O}_{3}$, which shows up at higher frequencies, is drawn to guide the eye. (b) Arrhenius plot (half-logarithmic plot of $\sigma^{\prime}$ vs $1000 / T$ ) to illustrate the change of conductivity with increasing temperature. Dashed and solid lines represent linear fits to determine activation energies $E_{\mathrm{A}}$, which range from $0.44(1) \mathrm{eV}$ to $0.59(1) \mathrm{eV}$. Nanoconfined $\mathrm{LiBH}_{4}-\mathrm{LiI} / \mathrm{Al}_{2} \mathrm{O}_{3}$ shows the highest conductivities. At room temperature $\left(25^{\circ} \mathrm{C}\right)$, its ion conductivity is slightly larger than $10^{-4} \mathrm{~S} \mathrm{~cm}^{-1}$; a conductivity of $10^{-3} \mathrm{~S} \mathrm{~cm}^{-1}$, needed to realize $\mathrm{Li}$ ion batteries, is reached at $66{ }^{\circ} \mathrm{C}$.

tional limit. Hence, the sample $\mathrm{LiI}-\mathrm{LiBH}_{4}$ with $20 \mathrm{~mol} \% \mathrm{LiI}$ was chosen for a more detailed study.

Figure 3a shows the corresponding Nyquist plot recorded at $25^{\circ} \mathrm{C}$; in Figure $3 \mathrm{~b}$, the temperature dependence of the ionic conductivity is displayed using an Arrhenius plot. For comparison, the Nyquist plots and conductivity data referring to $\mathrm{LiBH}_{4}-\mathrm{LiI}$ and nanoconfined $\mathrm{LiBH}_{4}$ are also shown. Capacitances $C$ ranged from 147 to $210 \mathrm{pF}$; values larger than $100 \mathrm{pF}$ typically indicate electrical relaxation processes influenced by interfacial regions. ${ }^{73}$ For nanoconfined compo- 
a)

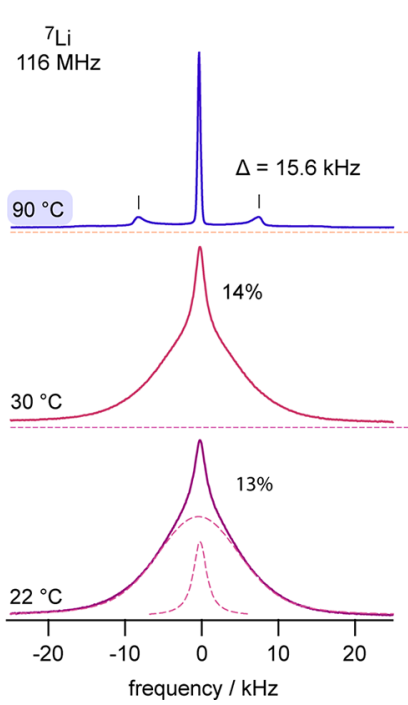

b)

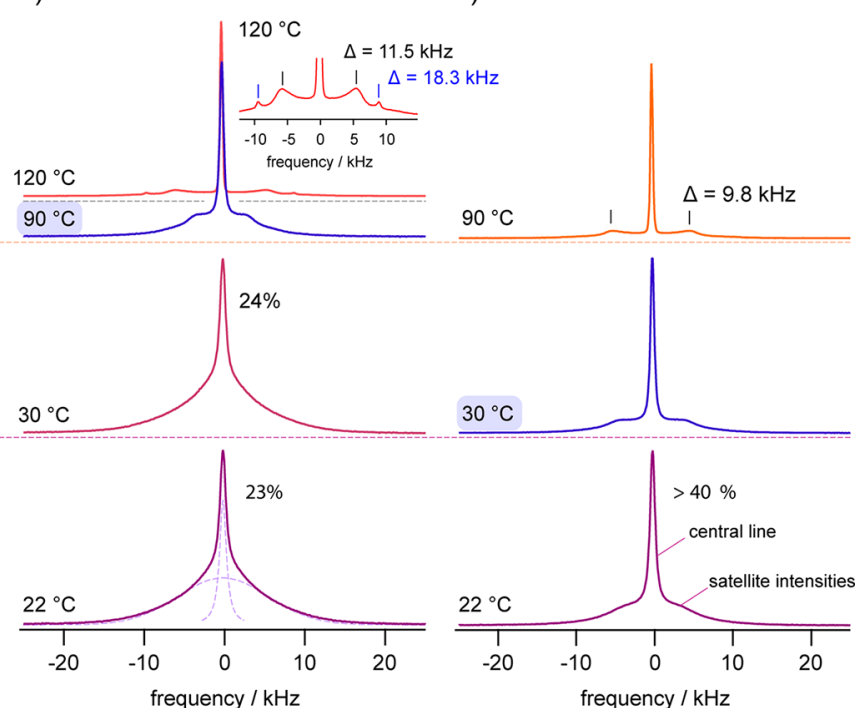

Figure 4. ${ }^{7} \mathrm{Li} \mathrm{NMR}$ spectra of (a) $\mathrm{LiBH}_{4}-\mathrm{LiI}$, (b) nanoconfined $\mathrm{LiBH}_{4} / \mathrm{Al}_{2} \mathrm{O}_{3}$ without $\mathrm{LiI}$, and (c) nanoconfined $\mathrm{LiBH} \mathrm{H}_{4}-\mathrm{LiI} / \mathrm{Al}_{2} \mathrm{O}_{3}$. Spectra were recorded at a Larmor frequency of $116 \mathrm{MHz}$ at the temperatures indicated. Dashed lines in parts a and $\mathrm{b}$ show the deconvolution of the entire line with appropriate Gaussian and Lorentzian functions to estimate the number fraction of mobile $\mathrm{Li}$ ions in these compounds. $\mathrm{For} \mathrm{LiBH}-\mathrm{LiI} / \mathrm{Al}_{2} \mathrm{O}_{3}$, the spectrum has almost adopted its final form at temperatures as low as $30{ }^{\circ} \mathrm{C}$. While the sharp line represents fast $\mathrm{Li}$ ions, the broader foot comprises both the central line of a fraction of slower $\mathrm{Li}$ ions and quadrupole intensities. The latter become visible as a sharp powder pattern at elevated temperature where dipole-dipole interactions are effectively averaged out due to rapid $\mathrm{Li}^{+}$exchange. See text for further information.

sites, it is widely believed that ion transport mainly occurs along the heterogeneous solid-solid interphase, that is, at the interface between the insulating oxide and the electrolyte. ${ }^{41-43}$ The exponents $n$ turned out to take values close to 1 meaning that the corresponding CPEs (constant phase elements) of all three samples behaved almost like an ideal RC unit. This observation is in line with the interpretation that the semicircle seen in the complex plane plot is governed by a response strongly influenced by grain boundary effects.

For $\mathrm{LiBH}_{4} / \mathrm{Al}_{2} \mathrm{O}_{3}$, a second semicircle is seen at lower frequencies, which is either too small to be detected or is absent in $\mathrm{LiBH}_{4}-\mathrm{LiI}$ and $\mathrm{LiBH}_{4}-\mathrm{LiI} / \mathrm{Al}_{2} \mathrm{O}_{3}$. The presence of the second semicircle suggests two different conducting phases. We attribute the main semicircle with the higher electrical relaxation rate to $\mathrm{LiBH}_{4}$ interacting with the oxide surface and the semicircle appearing at lower frequencies to $\mathrm{LiBH}_{4}$, which is farther away from the interface. This feature is also seen in ${ }^{7} \mathrm{Li}$ NMR spectroscopy; see Figure 4. We suppose that the addition of LiI led to both an increase of the high conducting regions and an enhancement of interfacial conductivity. Thus, for $\mathrm{LiBH}_{4}-\mathrm{LiI} / \mathrm{Al}_{2} \mathrm{O}_{3}$, the two contributions could not be resolved any longer when data recorded at $25{ }^{\circ} \mathrm{C}$ were analyzed.

The Arrhenius plot shown in Figure $3 \mathrm{~b}$ shows that ion transport at temperatures lower than $100{ }^{\circ} \mathrm{C}$ is clearly faster in the nanocomposites $\mathrm{LiBH}_{4}-\mathrm{LiI} / \mathrm{Al}_{2} \mathrm{O}_{3}$ and $\mathrm{LiBH}_{4}-\mathrm{LiI} / \mathrm{SiO}_{2}$ than in $\mathrm{LiBH}_{4}-\mathrm{LiI}$ and the nanoconfined samples $\mathrm{LiBH}_{4} /$ $\mathrm{Al}_{2} \mathrm{O}_{3}$ and $\mathrm{LiBH}_{4} / \mathrm{SiO}_{2}$. For instance, at room temperature (25 $\left.{ }^{\circ} \mathrm{C}\right)$, the ionic conductivity of $\mathrm{LiBH}_{4}-\mathrm{LiI} / \mathrm{Al}_{2} \mathrm{O}_{3}(0.1 \mathrm{mS}$ $\mathrm{cm}^{-1}$ ) was four times higher than that of $\mathrm{LiBH}_{4} / \mathrm{Al}_{2} \mathrm{O}_{3}$ and eight times higher than that of $\mathrm{LiBH}_{4}-\mathrm{LiI}$. In agreement with the trend for the increase in ionic conductivity, the activation energy for long-range ion transport decreased from $0.52(1) \mathrm{eV}$ for $\mathrm{LiBH}_{4}$ /oxide to $0.44(1) \mathrm{eV}$ for $\mathrm{LiBH}_{4}-\mathrm{LiI} /$ oxide. $\mathrm{LiBH}_{4}-$ LiI showed a rather high activation energy of $0.59 \mathrm{eV}$. These values are similar to those reported in literature for $\mathrm{LiBH}_{4} /$ $\mathrm{Al}_{2} \mathrm{O}_{3}$ and $\mathrm{LiI}-\mathrm{LiBH}_{4}$ systems. ${ }^{35,41}$

${ }^{7} \mathrm{Li}$ NMR line shapes of these samples, which have been recorded at room temperature and above, clearly revealed that $\mathrm{Li}^{+}$acts as mobile charge carrier. ${ }^{74}$ Selected lines are shown in Figure 4. For the $\mathrm{LiBH}_{4}-\mathrm{LiI}$ solid solution (see Figure 4a), the line at room temperature is composed of two contributions. The narrow line on top of the broader signal reflects the mobile Li spins whose jump rates exceed the line widths of this line in the rigid lattice, which turns out to be approximately 13 $\mathrm{kHz}$. Narrow NMR lines are caused by sufficiently fast $\mathrm{Li}^{+}$ exchange processes able to average local dipole-dipole interactions that lead to line broadening at low temperatures. In the case of $\mathrm{LiBH}_{4}-\mathrm{LiI}$, the line shape did not change much when going to $30{ }^{\circ} \mathrm{C}$; however, a significant change was seen at $90{ }^{\circ} \mathrm{C}$ where a fully narrowed central line appeared, that is, on top of a quadrupole powder pattern. This distinct pattern, showing sharp $90^{\circ}$ singularities separated by $\Delta=15.6 \mathrm{kHz}$, is characteristic for hexagonal $\mathrm{LiBH}_{4}(-\mathrm{LiI})$. A similar situation is seen for nanoconfined $\mathrm{LiBH}_{4} / \mathrm{Al}_{2} \mathrm{O}_{3}$ (see Figure $4 \mathrm{~b}$ ). However, the number fraction of rapid $\mathrm{Li}^{+}$ions was higher at 22 and 30 ${ }^{\circ} \mathrm{C}(24 \%)$ compared to that seen for nonconfined $\mathrm{LiBH}_{4}-\mathrm{LiI}$. This difference is in line with the slightly higher conductivity seen for $\mathrm{LiBH}_{4} / \mathrm{Al}_{2} \mathrm{O}_{3}$. It is worth noting that the motionally narrowed spectra recorded at $90{ }^{\circ} \mathrm{C}$ and at $120{ }^{\circ} \mathrm{C}$ were governed by electric quadrupole intensities being different than those of bulk $\mathrm{LiBH}_{4}$ and bulk $\mathrm{LiBH}_{4}-\mathrm{LiI}$. The spectra of nonconfined $\mathrm{LiBH}_{4}$ and nonconfined $\mathrm{LiBH}_{4}-\mathrm{LiI}$ reveal patterns produced by a symmetric electric field gradient (EFG) the ions were subjected to. They agree with those of similar systems studied earlier. ${ }^{40}$

In contrast to the nonconfined samples, the NMR line of nanoconfined $\mathrm{LiBH}_{4} / \mathrm{Al}_{2} \mathrm{O}_{3}$ recorded at $90{ }^{\circ} \mathrm{C}$ shows a nonsymmetric EFG. Its shape points to structural disorder and strain which the $\mathrm{Li}$ spins sense. $\Delta$ reduces from 15.6 to $11.5 \mathrm{kHz}$. Careful inspection of the powder pattern shows that 
another set of singularities is present (see inset of Figure $4 b$ ), which is characterized by $\Delta=18.3 \mathrm{kHz}$. Assuming axial symmetry for this pattern, we obtained a quadrupole coupling constant $\delta_{\mathrm{q}}$ of ca. $36.6 \mathrm{kHz}$ which was identical to that of bulk $\mathrm{LiBH}_{4}\left(\delta_{\mathrm{q}}=37 \mathrm{kHz}\right){ }^{75}$ The two quadrupole patterns represent the $\mathrm{Li}$ ions near the insulator surface $(\Delta=11.5$ $\mathrm{kHz}$ ) and the ions farther away, that is, located in the bulk regions $(\Delta=18.3 \mathrm{kHz})$. NMR revealed that these two species are exposed to different electric interactions. Two sources of electrical relaxation have also been seen in the corresponding Nyquist plot, vide supra.

For nanoconfined $\mathrm{LiBH}_{4}-\mathrm{LiI} / \mathrm{Al}_{2} \mathrm{O}_{3}$ (Figure 4c), we also observed a quadrupole powder pattern that is characterized by a lower $\Delta(=9.5 \mathrm{kHz})$ than that expected for bulk $\mathrm{LiBH}_{4}(-\mathrm{LiI})$. However, a pronounced pattern attributable to $\mathrm{Li}$ ions in bulk $\mathrm{LiBH}_{4}-\mathrm{LiI}$, as seen for $\mathrm{LiBH}_{4} / \mathrm{Al}_{2} \mathrm{O}_{3}$, was missing. Instead, already at temperatures as low as $30{ }^{\circ} \mathrm{C}$, an almost fully narrowed ${ }^{7} \mathrm{Li} \mathrm{NMR}$ line was observed which clearly points to very fast ion dynamics in this nanocomposite. ${ }^{74}$ We conclude that the majority of ions in this nanocomposite take part in rapid $\mathrm{Li}^{+}$exchange, which perfectly agrees with the conductivity trend seen in Figure $3 \mathrm{~b}$. From a structural point of view, the single EFG pattern observed points to a homogeneous sample as compared to nanoconfined $\mathrm{LiBH}_{4} /$ $\mathrm{Al}_{2} \mathrm{O}_{3}$. Presumably, if the ions reside in areas farther away from the surface of the oxide, they are subjected to a structurally stressed $\mathrm{LiBH}_{4}-\mathrm{LiI}$ phase with high ionic conductivity. This modified region, e.g., influenced by space charge zones, regions with higher defect density or increased structural disorder, may extend over almost the whole $\mathrm{LiBH}_{4}-\mathrm{LiI}$ phase leading to the enhancement in conductivity observed.

Note that all our samples were prepared under the same conditions and, therefore, the remarkable increase in ionic conduction for $\mathrm{LiBH}_{4}-\mathrm{LiI} / \mathrm{Al}_{2} \mathrm{O}_{3}$ seen by impedance spectroscopy and ${ }^{7} \mathrm{Li} \mathrm{NMR}$ is mainly attributed to the combined effects of anion substitution and interface engineering by nanoconfinement. Table 1 compares conductivities, activation

Table 1. Room Temperature Conductivities $(\sigma)$ of the Samples Studied by Impedance Spectroscopy ${ }^{d}$

\begin{tabular}{|c|c|c|c|}
\hline sample & $\underset{\left.\mathrm{cm}^{-1}\right)}{\sigma\left(25^{\circ} \mathrm{C}\right)}(\mathrm{S}$ & $E_{\mathrm{A}}(\mathrm{eV})$ & $\underset{\left.\mathbf{c m}^{-1} \mathbf{K}\right)}{\log _{10}(A)}(\mathrm{S}$ \\
\hline $\mathrm{LiBH}_{4} / \mathrm{MCM}-41$ & $2.29 \times 10^{-5}$ & $0.49(2)$ & $6.0(3)$ \\
\hline $\begin{array}{l}\mathrm{LiBH}_{4}-\mathrm{LiI} / \mathrm{MCM}-41 \text { comelt } \\
\text { infiltration }\end{array}$ & $3.86 \times 10^{-5}$ & $0.43(1)$ & $5.3(1)$ \\
\hline $\begin{array}{l}\mathrm{LiBH}_{4}-\mathrm{LiI} / \mathrm{MCM}-41 \\
\text { impregnation }\left(\mathrm{H}_{2} \mathrm{O}\right)\end{array}$ & $1.63 \times 10^{-5}$ & $0.52(2)$ & $6.5(3)$ \\
\hline $\begin{array}{l}\mathrm{LiBH}_{4}-\mathrm{LiI} / \mathrm{MCM}-41 \\
\text { impregnation }(\mathrm{EtOH})\end{array}$ & $4.57 \times 10^{-6}$ & $0.47(0)$ & $5.2(1)$ \\
\hline $\begin{array}{l}\mathrm{LiBH}_{4}-\mathrm{LiI} / \mathrm{SBA}-15 \text { comelt } \\
\text { infiltration }\end{array}$ & $1.29 \times 10^{-4}$ & $0.44(1)$ & $6.0(2)$ \\
\hline $\begin{array}{l}\mathrm{LiBH}_{4}-\mathrm{LiI} / \mathrm{Al}_{2} \mathrm{O}_{3} \text { comelt } \\
\text { infiltration }\end{array}$ & $1.27 \times 10^{-4}$ & $0.44(1)$ & $6.1(1)$ \\
\hline $\mathrm{LiBH}_{4}-\mathrm{LiI}$ & $1.54 \times 10^{-5}$ & $0.59(2)$ & $7.8(3)$ \\
\hline $\mathrm{LiBH}_{4}-\mathrm{LiNH}_{2}$ & $2.92 \times 10^{-6}$ & $\begin{array}{l}1.03(1)^{a} \\
0.19(1)^{b}\end{array}$ & $\begin{array}{l}1.8(1)^{a} \\
13(1)^{b}\end{array}$ \\
\hline $\mathrm{LiBH}_{4}-\mathrm{LiNH}_{2} / \mathrm{MCM}-41$ & $1.16 \times 10^{-4}$ & $0.43(1)^{c}$ & $5.5(2)$ \\
\hline
\end{tabular}

${ }^{a} E_{\mathrm{A}}$ determined in the temperature range from 30 to $50{ }^{\circ} \mathrm{C} .{ }^{b} E_{\mathrm{A}}$ determined in the temperature range from 60 to $85{ }^{\circ} \mathrm{C}$. ${ }^{c} E_{\mathrm{A}}$ determined in the temperature range from 30 to $85{ }^{\circ} \mathrm{C}$. ${ }^{d}$ The table also includes activation energies $\left(E_{\mathrm{A}}\right)$ and pre-factors $\left(\log _{10}(A)\right)$ of the Arrhenius laws used to approximate the temperature dependence of the ionic conductivity. If not stated otherwise, $E_{\mathrm{A}}$ has been determined in the temperature range from 25 to $130^{\circ} \mathrm{C}$. energies, and Arrhenius prefactors of the samples investigated. The slight differences in ionic conductivity of the nanocomposites prepared with different oxides (SBA-15, MCM-41, or $\mathrm{Al}_{2} \mathrm{O}_{3}$ ) are most likely due to differences in properties of these materials (see Figures S1 to S6 and Table S2). For example, the oxides differ in morphology, pore size, and pore size distribution, surface area, surface/interface energy, density of the surface groups, and the nature of the pores (e.g., pore corrugations). Detailed elucidation of the exact influence of these properties on ionic conductivity is, however, beyond the scope of the present work.

Importance of $\mathrm{LiBH}_{4}(-\mathrm{Lil}) / O x i d e$ Interface. To further demonstrate that both the interaction of $\mathrm{LiBH}_{4}$ with the oxide interface and partial anion substitution are important for the enhancement in ionic conductivity, we employed a preparation technique that is supposed to hinder the interaction of $\mathrm{LiBH}_{4}$ with the oxide interface but still form $\mathrm{LiBH}_{4}-\mathrm{LiI}$ in the pores. This comparison showed that the nanocomposites prepared by coinfiltration of a physical mixture of $\mathrm{LiBH}_{4}$ and LiI exhibited much higher conductivities than those which were prepared via solution impregnation (Table 1). If we first add LiI to fill the pores via impregnation with $\mathrm{LiI} / \mathrm{H}_{2} \mathrm{O}$ or $\mathrm{LiI} / \mathrm{C}_{2} \mathrm{H}_{5} \mathrm{OH}$ solution and then add $\mathrm{LiBH}_{4}$ by melt infiltration as a second step, we see that the resulting ionic conductivity is significantly lower. At first glance, this difference is surprising as results from XRD and IR (DRIFTS) suggest that both samples have similar structures (cf. Figure 1 and Figure S9). We attribute the marked change seen in conductivity to the fact that if LiI is added first, we do not have the original $\mathrm{SiOH}$ groups present at the interface anymore (see Figure $S 9$ for the loss of silanol groups in $\left.\mathrm{LiI} / \mathrm{SiO}_{2}\right)$. This changed the properties of the interface with the $\mathrm{LiBH}_{4}$, and as a result, the conductivity is not as high as that with the other preparation technique.

$\mathrm{LiBH}_{4}-\mathrm{LiNH}_{2}$ System. To demonstrate the general applicability of the strategy outlined above, we measured also the conductivity of another nanoconfined electrolyte containing two complex anions, i.e., nanoconfined $\mathrm{LiBH}_{4}-\mathrm{LiNH}_{2}$. $\mathrm{XRD}$ revealed the formation of two new phases,namel, $\mathrm{Li}_{2}\left(\mathrm{BH}_{4}\right)\left(\mathrm{NH}_{2}\right)$ and $\mathrm{Li}_{4}\left(\mathrm{BH}_{4}\right)\left(\mathrm{NH}_{2}\right)_{3}$ (see Figure 5a). This is unlike the $\mathrm{LiBH}_{4}-\mathrm{LiX}$ systems where the high temperature phase of $\mathrm{LiBH}_{4}$ was stabilized through the replacement of $\mathrm{BH}_{4}{ }^{-}$by halides causing lattice strain but no change in crystal structure. For nanoconfined $\mathrm{LiBH}_{4}-\mathrm{LiNH}_{2} / \mathrm{MCM}-41$, XRD points to a loss of crystallinity, that is, long-range order. As mentioned above, the same feature was observed for the $\mathrm{LiBH}_{4}-\mathrm{LiI}$ solid solutions. In addition, results from DRIFTS measurements (see Figure $5 \mathrm{~b}$ ) revealed that the characteristic vibrations related to $\mathrm{LiBH}_{4}-\mathrm{LiNH}_{2},\left(1000\right.$ to $1500 \mathrm{~cm}^{-1}$ and 2000 to $2800 \mathrm{~cm}^{-1}\left(\mathrm{BH}_{4}^{-}\right), 1500$ to $1600 \mathrm{~cm}^{-1}$ and 3200 to $3300 \mathrm{~cm}^{-1}\left(\mathrm{NH}_{2}^{-}\right)$, shifted toward lower wavenumbers and became significantly broader upon nanoconfinement. The bands related to the surface silanol groups $\left(3700 \mathrm{~cm}^{-1}\right)$ were absent, as seen for nanoconfined $\mathrm{LiBH}_{4}-\mathrm{LiI}$. Hence, we conclude that the $\mathrm{LiBH}_{4}-\mathrm{LiNH}_{2}$ composite was successfully infiltrated into the nanopores of MCM-41 leading to profound changes of its structure. ${ }^{66}$

In Figure 6, the ionic conductivities of selected $\mathrm{LiBH}_{4}-$ $\mathrm{LiNH}_{2}$ samples are shown. First, when compared to $\mathrm{LiBH}_{4}$, it is clear that the addition of $\mathrm{LiNH}_{2}$ to $\mathrm{LiBH}_{4}$ increases the room temperature ionic conductivity by approximately 2 orders of magnitude. This increase is ascribed to the formation of $\mathrm{Li}_{2}\left(\mathrm{BH}_{4}\right)\left(\mathrm{NH}_{2}\right) .{ }^{39}$ The sudden increase in conductivity of $\mathrm{Li}_{2}\left(\mathrm{BH}_{4}\right)\left(\mathrm{NH}_{2}\right)$ at approximately $35{ }^{\circ} \mathrm{C}$ originates from a 
a)

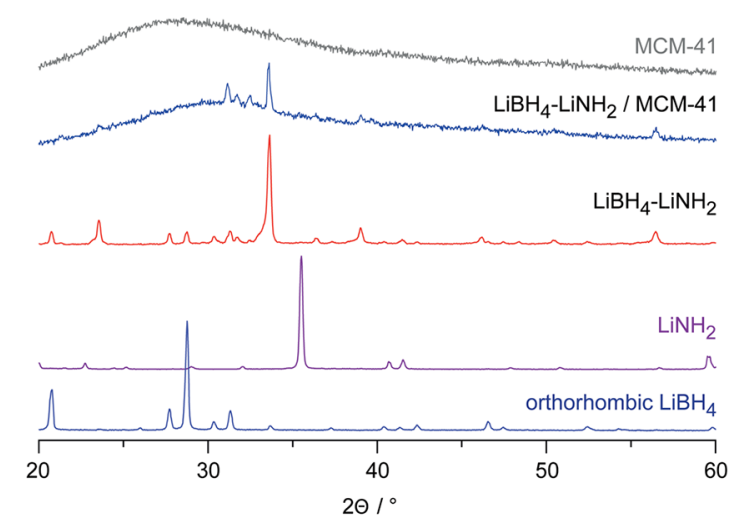

b)

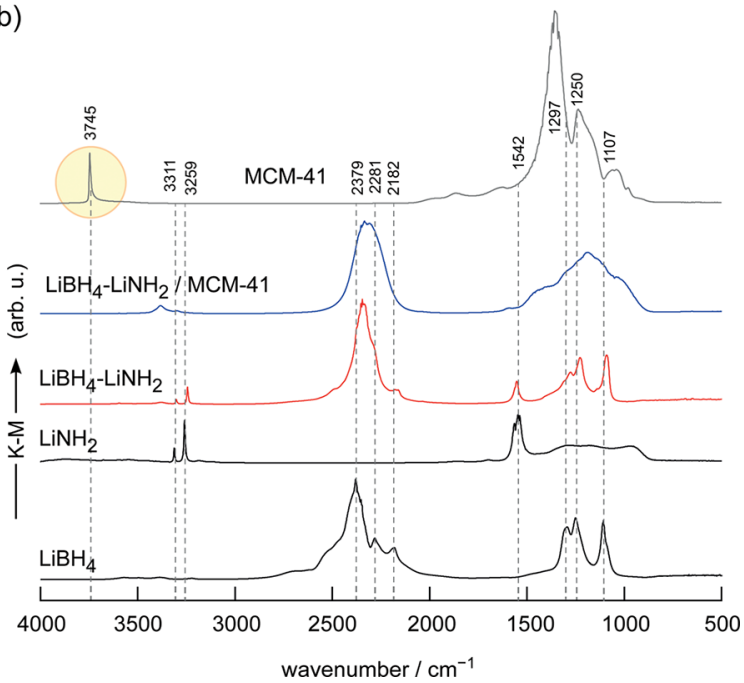

Figure 5. (a) X-ray powder diffraction patterns of nanoconfined and nonconfined $\mathrm{LiBH}_{4}-\mathrm{LiNH}_{2}$. For comparison, the expected patterns of orthorhombic $\mathrm{LiBH}_{4}$ and $\mathrm{LiNH}_{2}$ are also shown. The pattern at the top represents that of the oxide substrate, $\mathrm{SiO}_{2}$. (b) DRIFT spectra of the samples shown in part a; the spectra reveal broadening of the signals, which shift toward lower wavenumbers upon nanoconfinement. Those bands which results from silanol $\mathrm{OH}$ groups are absent for $\mathrm{LiBH}_{4}-\mathrm{LiNH}_{2} / \mathrm{SiO}_{2}$ indicating surface reactions between the electrolyte and the surface of the oxide. See text for further explanation.

structural phase change leading to a highly conducting phase at temperature higher than $40{ }^{\circ} \mathrm{C}$. Nanoconfined $\mathrm{LiBH}_{4}-\mathrm{LiNH}_{2} /$ MCM-41 showed an even better ionic conductivity at this temperature; remarkably, this high ionic conductivity was also preserved at lower temperatures. When compared to $\mathrm{LiBH}_{4}$ and $\mathrm{LiBH}_{4}-\mathrm{LiNH}_{2}$, the room temperature ionic conductivity of nanoconfined $\mathrm{LiBH}_{4}-\mathrm{LiNH}_{2} / \mathrm{MCM}-41$ was higher by 4 and 2 orders of magnitude, respectively. It also exceeded that of nanoconfined $\mathrm{LiBH}_{4} / \mathrm{MCM}-41$ by a factor of 2 if conductivities at $T=30{ }^{\circ} \mathrm{C}$ were considered (cf. Figure 6). At approximately $50{ }^{\circ} \mathrm{C}, \mathrm{LiBH}_{4}-\mathrm{LiNH}_{2} / \mathrm{MCM}-41$ reached a conductivity of $1 \mathrm{mS} \mathrm{cm}^{-1}$. Below $45^{\circ} \mathrm{C}$, the overall activation energy governing ion transport in $\mathrm{LiBH}_{4}-\mathrm{LiNH}_{2} / \mathrm{MCM}-41$ $(0.43 \mathrm{eV})$ is comparable to that of bulk $\mathrm{LiBH}_{4}$ and significantly lower than that of $\mathrm{LiBH}_{4}-\mathrm{LiNH}_{2}$ at room temperature. For $\mathrm{LiBH}_{4} / \mathrm{MCM}-41$ and $\mathrm{LiBH}_{4}-\mathrm{LiNH}_{2}$ at higher temperatures, we see that $E_{\mathrm{A}}$ is somewhat lower, 0.26 and $0.19 \mathrm{eV}$, respectively; see Figure 6 and Table 1. On the basis of the results from the DRIFTS measurements, the remarkable

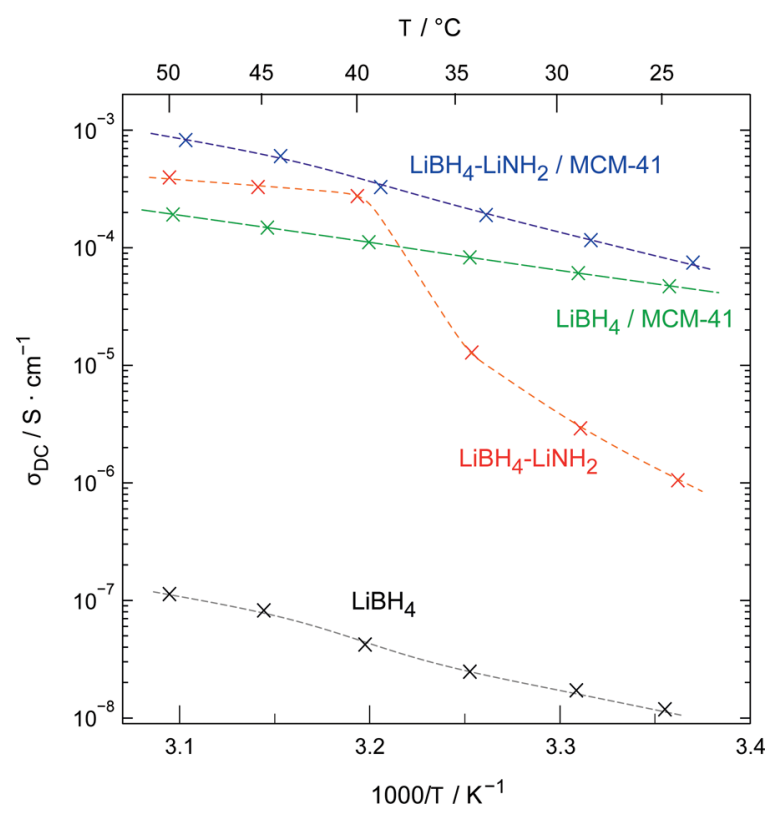

Figure 6. Ionic conductivity of nanoconfined $\mathrm{LiBH}_{4}-\mathrm{LiNH}_{2} / \mathrm{SiO}_{2}$ as a function of the inverse temperature. For comparison, data on $\mathrm{LiBH}_{4} / \mathrm{SiO}_{2}$, nonconfined $\mathrm{LiBH}_{4}-\mathrm{LiNH}_{2}$ and bulk $\mathrm{LiBH}_{4}$ are also included. The lines are to guide the eye.

increase in ionic conductivity is again attributed to the combined effect of anion substitution and interface effects, as observed for nanoconfined $\mathrm{LiBH}_{4}-\mathrm{LiI}$. These results illustrate that the synergistic effects of nanoconfinement, that is, interface engineering, and partial ion substitution is applicable to different Li-based electrolytes in various nonconducting nanoporous scaffolds.

\section{CONCLUSION}

We have shown how two routes, namely, ion substitution and interface engineering, can be effectively combined to enhance the ionic conductivity of solid-state electrolytes. Using complex hydrides as model systems, we developed an approach where anion substituted $\mathrm{LiBH}_{4} \quad\left(\mathrm{Li}_{2}\left(\mathrm{BH}_{4}\right)_{x} \mathrm{I}_{1-x}\right.$ and $\left.\mathrm{Li}_{2}\left(\mathrm{BH}_{4}\right)_{x}\left(\mathrm{NH}_{2}\right)_{1-x}\right)$ are confined in nanoporous $\mathrm{SiO}_{2}$ or $\mathrm{Al}_{2} \mathrm{O}_{3}$ in order to exploit both the effect of ion substitution and nanoconfinement or interface engineering to boost the Li-ion conductivities of $\mathrm{LiBH}_{4}$ at ambient conditions. Indeed, the ionic conductivity of the nanocomposites of $\mathrm{LiBH}_{4}-\mathrm{LiI} / \mathrm{Al}_{2} \mathrm{O}_{3}$ reached $0.1 \mathrm{mS} \mathrm{cm}{ }^{-1}$ at room temperature. The room temperature conductivities of nonsubstituted $\mathrm{LiBH}_{4} / \mathrm{Al}_{2} \mathrm{O}_{3}$ and $\mathrm{LiBH}_{4}-\mathrm{LiI}$ without nanoconfinement were 1 order of magnitude lower. Activation energies are in line with this trend, with 0.44, 0.52, and $0.59 \mathrm{eV}$ for the $\mathrm{LiBH}_{4}-\mathrm{LiI} / \mathrm{Al}_{2} \mathrm{O}_{3}$, $\mathrm{LiBH}_{4} / \mathrm{Al}_{2} \mathrm{O}_{3}$, and $\mathrm{LiBH}_{4}-\mathrm{LiI}$, respectively. Detailed structural investigations and ${ }^{7} \mathrm{Li}$ NMR line shape measurements show that the combined effects of interaction with the interface of the oxides and phase stabilization due to partial anion substitution (by the iodide anion) produces faster $\mathrm{Li}^{+}$diffusion pathways in $\mathrm{LiBH}_{4}-\mathrm{LiI} /$ oxide than those in the case of $\mathrm{LiBH}_{4}$ / oxide and $\mathrm{LiBH}_{4}-\mathrm{LiI}$. Results on $\mathrm{LiBH}_{4}-\mathrm{LiNH}_{2}$ confined in mesoporous silica (MCM-41) show that this concept is also applicable to other Li-bearing hydrides. The enhancement effect depends also on the type and property of the scaffold. Our study clearly shows that combining partial anion substitution and nanoconfinement is a very promising 
approach to achieve high room temperature ionic conductivities in solid-state ion conductors.

\section{ASSOCIATED CONTENT}

\section{SI Supporting Information}

The Supporting Information is available free of charge at https://pubs.acs.org/doi/10.1021/acs.jpcc.9b10607.

Calculation of the amount of material needed for melt infiltration to reach the desired pore filling; physisorption data; high-resolution scanning electron microscopy images; additional XRD patterns and DRIFTS data; further conductivity Arrhenius plot comparing different supports; comparison of room temperature conductivity values of samples with varying LiI content (0 to $40 \mathrm{~mol}$ \%) (PDF)

\section{AUTHOR INFORMATION}

\section{Corresponding Authors}

Petra E. de Jongh - Inorganic Chemistry and Catalysis, Debye Institute for Nanomaterials Science, Utrecht University, 3584 CG Utrecht, Netherlands; 이이.org/0000-0002-22162620; Email: P.E.deJongh@uu.nl

Peter Ngene - Inorganic Chemistry and Catalysis, Debye Institute for Nanomaterials Science, Utrecht University, 3584 CG Utrecht, Netherlands; 이이.org/0000-0003-36910623; Email: P.ngene@uu.nl

\section{Authors}

Roman Zettl - Institute for Chemistry and Technology of Materials, and Christian Doppler Laboratory for Lithium Batteries, Graz University of Technology (NAWI Graz), 8010 Graz, Austria; Inorganic Chemistry and Catalysis, Debye Institute for Nanomaterials Science, Utrecht University, 3584 CG Utrecht, Netherlands

Laura de Kort - Inorganic Chemistry and Catalysis, Debye Institute for Nanomaterials Science, Utrecht University, 3584 CG Utrecht, Netherlands

Maria Gombotz - Institute for Chemistry and Technology of Materials, and Christian Doppler Laboratory for Lithium Batteries, Graz University of Technology (NAWI Graz), 8010 Graz, Austria

H. Martin R. Wilkening - Institute for Chemistry and Technology of Materials, and Christian Doppler Laboratory for Lithium Batteries, Graz University of Technology (NAWI Graz), 8010 Graz, Austria; (1) orcid.org/0000-0001-97064892

Complete contact information is available at: https://pubs.acs.org/10.1021/acs.jpcc.9b10607

\section{Author Contributions}

R.Z. and L.d.K. contributed equally to this work.

Notes

The authors declare no competing financial interest.

\section{ACKNOWLEDGMENTS}

We greatly appreciate funding from the NWO materials for sustainability (Mat4Sus-739.017.009) and NWO-ECHO (712.015.005) grants. P.N. received funding from the European Research Council (ERC) under the European Union's Horizon 2020 research and innovation programme (ERC2014-CoG No 648991). R.Z. and H.M.R.W. thank the Austrian Federal Ministry for Science, Research and Economy as well as the Christian-Doppler Forschungsgesellschaft for financial support; further support by the FFG (The Austrian Research Promotion Agency) in the frame of the project Safe Battery is also acknowledged. R.Z. thanks the project SOLABAT (project no. 853627) funded by the Klima- und Energiefonds of FFG for additional support. Furthermore, we thank Sander Lambregts and Hans Meeldijk for physisorption and SEM measurements as well as Oscar Brandt Corstius for the synthesis of MCM-41.

\section{REFERENCES}

(1) Manthiram, A.; Yu, X. W.; Wang, S. F. Lithium battery chemistries enabled by solid-state electrolytes. Nat. Rev. Mater. 2017 2 (4), 16103.

(2) Janek, J.; Zeier, W. G. A solid future for battery development. Nat. Energy 2016, 1, 16141.

(3) Mikhaylik, Y. V.; Akridge, J. R. Polysulfide shuttle study in the Li/S battery system. J. Electrochem. Soc. 2004, 151 (11), A1969A1976.

(4) Kim, J. G.; Son, B.; Mukherjee, S.; Schuppert, N.; Bates, A.; Kwon, O.; Choi, M. J.; Chung, H. Y.; Park, S. A review of lithium and non-lithium based solid state batteries. J. Power Sources 2015, 282, 299-322.

(5) Sun, C. W.; Liu, J.; Gong, Y. D.; Wilkinson, D. P.; Zhang, J. J. Recent advances in all-solid-state rechargeable lithium batteries. Nano Energy 2017, 33, 363-386.

(6) Knauth, P. Inorganic solid Li ion conductors: An overview. Solid State Ionics 2009, 180 (14-16), 911-916.

(7) Takada, K. Progress and prospective of solid-state lithium batteries. Acta Mater. 2013, 61 (3), 759-770.

(8) Li, J. C.; Ma, C.; Chi, M. F.; Liang, C. D.; Dudney, N. J. Solid electrolyte: the key for high-voltage lithium batteries. Adv. Energy Mater. 2015, 5 (4), 1401408.

(9) Thangadurai, V.; Narayanan, S.; Pinzaru, D. Garnet-type solidstate fast $\mathrm{Li}$ ion conductors for $\mathrm{Li}$ batteries: Critical review. Chem. Soc. Rev. 2014, 43 (13), 4714-4727.

(10) Bohnke, O.; Bohnke, C.; Fourquet, J. L. Mechanism of ionic conduction and electrochemical intercalation of lithium into the perovskite lanthanum lithium titanate. Solid State Ionics 1996, 91, 2131

(11) Li, J.; Lin, Y.; Yao, H. H.; Yuan, C. F.; Liu, J. Tuning thin-film electrolyte for lithium battery by grafting cyclic carbonate and combed poly(ethylene oxide) on polysiloxane. ChemSusChem 2014, 7 (7), 1901-1908.

(12) Hayashi, A.; Sakuda, A.; Tatsumisago, M. Development of sulfide solid electrolytes and interface formation processes for bulktype all-solid-state $\mathrm{Li}$ and $\mathrm{Na}$ batteries. Front. Energy Res. 2016, 4, 25.

(13) de Jongh, P. E.; Blanchard, D.; Matsuo, M.; Udovic, T. J.; Orimo, S. Complex hydrides as room-temperature solid electrolytes for rechargeable batteries. Appl. Phys. A: Mater. Sci. Process. 2016, 122, 251

(14) Matsuo, M.; Orimo, S. Lithium fast-ionic conduction in complex hydrides: review and prospects. Adv. Energy Mater. 2011, 1 (2), 161-172.

(15) Lu, Z. H.; Ciucci, F. Metal borohydrides as electrolytes for solid-state $\mathrm{Li}, \mathrm{Na}, \mathrm{Mg}$, and $\mathrm{Ca}$ batteries: A first-principles study. Chem. Mater. 2017, 29 (21), 9308-9319.

(16) Møller, K.; Sheppard, D.; Ravnsbæk, D.; Buckley, C.; Akiba, E.; Li, H.-W.; Jensen, T. Complex metal hydrides for hydrogen, thermal and electrochemical energy storage. Energies 2017, 10 (10), 1645.

(17) Yoshida, K.; Sato, T.; Unemoto, A.; Matsuo, M.; Ikeshoji, T.; Udovic, T. J.; Orimo, S. Fast sodium ionic conduction in $\mathrm{Na}_{2} \mathrm{~B}_{10} \mathrm{H}_{10^{-}}$ $\mathrm{Na}_{2} \mathrm{~B}_{12} \mathrm{H}_{12}$ pseudo-binary complex hydride and application to a bulktype all-solid-state battery. Appl. Phys. Lett. 2017, 110 (10), 103901.

(18) Sakintuna, B.; Lamari-Darkrim, F.; Hirscher, M. Metal hydride materials for solid hydrogen storage: A review. Int. J. Hydrogen Energy 2007, 32 (9), 1121-1140. 
(19) Zuttel, A.; Wenger, P.; Rentsch, S.; Sudan, P.; Mauron, P.; Emmenegger, C. $\mathrm{LiBH}_{4}$ a new hydrogen storage material. J. Power Sources 2003, 118 (1-2), 1-7.

(20) Umegaki, T.; Yan, J. M.; Zhang, X. B.; Shioyama, H.; Kuriyama, $\mathrm{N}$.; Xu, Q. Boron- and nitrogen-based chemical hydrogen storage materials. Int. J. Hydrogen Energy 2009, 34 (5), 2303-2311.

(21) Schuth, F.; Bogdanovic, B.; Felderhoff, M. Light metal hydrides and complex hydrides for hydrogen storage. Chem. Commun. 2004, 20, 2249-2258.

(22) Duchene, L.; Kuhnel, R.-S.; Stilp, E.; Cuervo Reyes, E.; Remhof, A.; Hagemann, H.; Battaglia, C. A stable $3 \mathrm{~V}$ all-solid-state sodium-ion battery based on a closo-borate electrolyte. Energy Environ. Sci. 2017, 10 (12), 2609-2615.

(23) Asakura, R.; Duchene, L.; Kuhnel, R. S.; Remhof, A.; Hagemann, H.; Battaglia, C. Electrochemical oxidative stability of hydroborate-based solid state electrolytes. ACS Appl. Energy Mater. 2019, 2 (9), 6924-6930.

(24) Kim, S.; Oguchi, H.; Toyama, N.; Sato, T.; Takagi, S.; Otomo, T.; Arunkumar, D.; Kuwata, N.; Kawamura, J.; Orimo, S. A complex hydride lithium superionic conductor for high-energy-density allsolid-state lithium metal batteries. Nat. Commun. 2019, 10, 1081.

(25) Matsuo, M.; Nakamori, Y.; Orimo, S.; Maekawa, H.; Takamura, H. Lithium superionic conduction in lithium borohydride accompanied by structural transition. Appl. Phys. Lett. 2007, 91 (22), 224103.

(26) Soulié, J. P.; Renaudin, G.; Černý, R.; Yvon, K. Lithium borohydride $\mathrm{LiBH}_{4}$ : I. Crystal structure. J. Alloys Compd. 2002, 346 (1), 200-205.

(27) Aeberhard, P. C.; Refson, K.; David, W. I. F. Molecular dynamics investigation of the disordered crystal structure of hexagonal $\mathrm{LiBH}_{4}$. Phys. Chem. Chem. Phys. 2013, 15 (21), 8081-8087.

(28) Matsuo, M.; Takamura, H.; Maekawa, H.; Li, H. W.; Orimo, S. Stabilization of lithium superionic conduction phase and enhancement of conductivity of $\mathrm{LiBH}_{4}$ by $\mathrm{LiCl}$ addition. Appl. Phys. Lett. 2009, 94 (8), 084103.

(29) Oguchi, H.; Matsuo, M.; Hummelshoj, J. S.; Vegge, T.; Norskov, J. K.; Sato, T.; Miura, Y.; Takamura, H.; Maekawa, H.; Orimo, S. Experimental and computational studies on structural transitions in the $\mathrm{LiBH}_{4}$-LiI pseudobinary system. Appl. Phys. Lett. 2009, 94 (14), 141912.

(30) Matsuo, M.; Remhof, A.; Martelli, P.; Caputo, R.; Ernst, M.; Miura, Y.; Sato, T.; Oguchi, H.; Maekawa, H.; Takamura.; et al. Complex hydrides with $\left(\mathrm{BH}_{4}\right)^{-}$and $\left(\mathrm{NH}_{2}\right)^{-}$anions as new lithium fast-ion conductors. J. Am. Chem. Soc. 2009, 131 (45), 16389.

(31) Yao, Z. P.; Kim, S.; Michel, K.; Zhang, Y. S.; Aykol, M.; Wolverton, C. Stability and conductivity of cation- and anionsubstituted $\mathrm{LiBH}_{4}$-based solid-state electrolytes. Phys. Rev. Mater. 2018, 2 (6), 065402.

(32) Mezaki, T.; Kuronuma, Y.; Oikawa, I.; Kamegawa, A.; Takamura, H. Li-ion conductivity and phase stability of Ca-doped $\mathrm{LiBH}_{4}$ under high pressure. Inorg. Chem. 2016, 55 (20), 1048410489.

(33) Ley, M. B.; Jorgensen, M.; Cerny, R.; Filinchuk, Y.; Jensen, T. R. From $\mathrm{M}\left(\mathrm{BH}_{4}\right)_{3}(\mathrm{M}=\mathrm{La}, \mathrm{Ce})$ Borohydride frameworks to controllable synthesis of porous hydrides and ion conductors. Inorg. Chem. 2016, 55 (19), 9748-9756.

(34) Rude, L. H.; Groppo, E.; Arnbjerg, L. M.; Ravnsbaek, D. B.; Malmkjaer, R. A.; Filinchuk, Y.; Baricco, M.; Besenbacher, F.; Jensen, T. R. Iodide substitution in lithium borohydride, $\mathrm{LiBH}_{4}$-LiI. J. Alloys Compd. 2011, 509 (33), 8299-8305.

(35) Miyazaki, R.; Karahashi, T.; Kumatani, N.; Noda, Y.; Ando, M.; Takamura, H.; Matsuo, M.; Orimo, S.; Maekawa, H. Room temperature lithium fast-ion conduction and phase relationship of LiI stabilized $\mathrm{LiBH}_{4}$. Solid State Ionics 2011, 192 (1), 143-147.

(36) Sveinbjornsson, D.; Myrdal, J. S. G.; Blanchard, D.; Bentzen, J. J.; Hirata, T.; Mogensen, M. B.; Norby, P.; Orimo, S. I.; Vegge, T. Effect of heat treatment on the lithium ion conduction of the $\mathrm{LiBH}_{4}$ Lil solid solution. J. Phys. Chem. C 2013, 117 (7), 3249-3257.
(37) Maekawa, H.; Matsuo, M.; Takamura, H.; Ando, M.; Noda, Y.; Karahashi, T.; Orimo, S. I. Halide-stabilized $\mathrm{LiBH}_{4}$, a roomtemperature lithium fast-ion conductor. J. Am. Chem. Soc. 2009, 131 (3), 894.

(38) Stephenson, C. C.; Rice, D. W.; Stockmayer, W. H. Orderdisorder transitions in the alkali borohydrides. J. Chem. Phys. 1955, 23 (10), 1960-1960.

(39) Yan, Y. G.; Kuhnel, R. S.; Remhof, A.; Duchene, L.; Reyes, E. C.; Rentsch, D.; Lodziana, Z.; Battaglia, C. A lithium amideborohydride solid-state electrolyte with lithium-ion conductivities comparable to liquid electrolytes. Adv. Energy Mater. 2017, 7 (19), 1700294.

(40) Blanchard, D.; Nale, A.; Sveinbjornsson, D.; Eggenhuisen, T. M.; Verkuijlen, M. H. W.; Suwarno; Vegge, T.; Kentgens, A. P. M.; de Jongh, P. E. Nanoconfined $\mathrm{LiBH}_{4}$ as a fast lithium ion conductor. $A d v$. Funct. Mater. 2015, 25 (2), 184-192.

(41) Epp, V.; Wilkening, M. Motion of $\mathrm{Li}^{+}$in nanoengineered $\mathrm{LiBH}_{4}$ and $\mathrm{LiBH}_{4}: \mathrm{Al}_{2} \mathrm{O}_{3}$ comparison with the microcrystalline form. ChemPhysChem 2013, 14 (16), 3706-3713.

(42) Choi, Y. S.; Lee, Y. S.; Oh, K. H.; Cho, Y. W. Interfaceenhanced $\mathrm{Li}$ ion conduction in a $\mathrm{LiBH}_{4}-\mathrm{SiO}_{2}$ solid electrolyte. Phys. Chem. Chem. Phys. 2016, 18 (32), 22540-22547.

(43) Choi, Y. S.; Lee, Y. S.; Choi, D. J.; Chae, K. H.; Oh, K. H.; Cho, $\mathrm{Y}$. W. Enhanced $\mathrm{Li}$ ion conductivity in $\mathrm{LiBH}_{4}-\mathrm{Al}_{2} \mathrm{O}_{3}$ mixture via interface engineering. J. Phys. Chem. C 2017, 121 (47), 26209-26215.

(44) Gutowska, A.; Li, L. Y.; Shin, Y. S.; Wang, C. M. M.; Li, X. H. S.; Linehan, J. C.; Smith, R. S.; Kay, B. D.; Schmid, B.; Shaw, W.; et al. Nanoscaffold mediates hydrogen release and the reactivity of ammonia borane. Angew. Chem., Int. Ed. 2005, 44 (23), 3578-3582.

(45) Berube, V.; Radtke, G.; Dresselhaus, M.; Chen, G. Size effects on the hydrogen storage properties of nanostructured metal hydrides: A review. Int. J. Energy Res. 2007, 31 (6-7), 637-663.

(46) de Jongh, P. E.; Adelhelm, P. Nanosizing and nanoconfinement: new strategies towards meeting hydrogen storage goals. ChemSusChem 2010, 3 (12), 1332-1348.

(47) Ngene, P.; van Zwienen, M.; de Jongh, P. E. Reversibility of the hydrogen desorption from $\mathrm{LiBH}_{4}$ : a synergetic effect of nanoconfinement and Ni addition. Chem. Commun. 2009, 46 (43), 8201-8203.

(48) Suwarno; Ngene, P.; Nale, A.; Eggenhuisen, T. M.; Oschatz, M.; Embs, J. P.; Remhof, A.; de Jongh, P. E. Confinement effects for lithium borohydride: comparing silica and carbon scaffolds. J. Phys. Chem. C 2017, 121 (8), 4197-4205.

(49) Maier, J. Ionic-conduction in space charge regions. Prog. Solid State Chem. 1995, 23 (3), 171-263.

(50) Verdal, N.; Udovic, T. J.; Rush, J. J.; Liu, X. F.; Majzoub, E. H.; Vajo, J. J.; Gross, A. F. Dynamical perturbations of tetrahydroborate anions in $\mathrm{LiBH}_{4}$ due to nanoconfinement in controlled-pore carbon scaffolds. J. Phys. Chem. C 2013, 117 (35), 17983-17995.

(51) Breuer, S.; Uitz, M.; Wilkening, H. M. R. Rapid Li ion dynamics in the interfacial regions of nanocrystalline solids. J. Phys. Chem. Lett. 2018, 9 (8), 2093-2097.

(52) de Jongh, P. E.; Eggenhuisen, T. M. Melt infiltration: an emerging technique for the preparation of novel functional nanostructured materials. Adv. Mater. 2013, 25 (46), 6672-6690.

(53) Unemoto, A.; Yasaku, S.; Nogami, G.; Tazawa, M.; Taniguchi, M.; Matsuo, M.; Ikeshoji, T.; Orimo, S. Development of bulk-type allsolid-state lithium-sulfur battery using $\mathrm{LiBH}_{4}$ electrolyte. Appl. Phys. Lett. 2014, 105 (8), 083901.

(54) Das, S.; Ngene, P.; Norby, P.; Vegge, T.; de Jongh, P. E.; Blanchard, D. All-solid-state lithium-sulfur battery based on a nanoconfined $\mathrm{LiBH}_{4}$ electrolyte. J. Electrochem. Soc. 2016, 163 (9), A2029-A2034.

(55) Lefevr, J.; Cervini, L.; Griffin, J. M.; Blanchard, D. Lithium conductivity and ions dynamics in $\mathrm{LiBH}_{4} / \mathrm{SiO}_{2}$ solid electrolytes studied by solid-state NMR and quasi-elastic neutron scattering and applied in lithium sulfur batteries. J. Phys. Chem. C 2018, 122 (27), $15264-15275$.

(56) Cheng, C.-F.; Zhou, W.; Ho Park, D.; Klinowski, J.; Hargreaves, M.; Gladden, L. F. Controlling the channel diameter of the 
mesoporous molecular sieve MCM-41. J. Chem. Soc., Faraday Trans. 1997, 93 (2), 359-363.

(57) Zhao, D. Y.; Feng, J. L.; Huo, Q. S.; Melosh, N.; Fredrickson, G. H.; Chmelka, B. F.; Stucky, G. D. Triblock copolymer syntheses of mesoporous silica with periodic 50 to 300 angstrom pores. Science 1998, 279 (5350), 548-552.

(58) Hartman, M. R.; Rush, J. J.; Udovic, T. J.; Bowman, R. C.; Hwang, S. J. Structure and vibrational dynamics of isotopically labeled lithium borohydride using neutron diffraction and spectroscopy. J. Solid State Chem. 2007, 180 (4), 1298-1305.

(59) Filinchuk, Y.; Chernyshov, D.; Cerny, R. Lightest borohydride probed by synchrotron X-ray diffraction: Experiment calls for a new theoretical revision. J. Phys. Chem. C 2008, 112 (28), 10579-10584.

(60) Hanawalt, J. D.; Rinn, H. W.; Frevel, L. K. Chemical analysis by $\mathrm{X}$-ray diffraction - Classification and use of X-ray diffraction patterns. Ind. Eng. Chem., Anal. Ed. 1938, 10, 0457-0512.

(61) Posnjak, E. W. R. Crystal structure of alkali halogenides. J. Wash. Acad. Sci. 1922, 12, 248-251.

(62) Royer, L. Sur les accolements reguliers de cristaux d'especes differentes. C. R. Hebd. Seances Acad. Sci. 1925, 180, 2050.

(63) Harvey, K. B.; Mcquaker, N. R. Low temperature infrared and raman spectra of lithium borohydride. Can. J. Chem. 1971, 49 (20), 3282.

(64) D’Anna, V.; Spyratou, A.; Sharma, M.; Hagemann, H. FT-IR spectra of inorganic borohydrides. Spectrochim. Acta, Part A 2014, 128, 902-906.

(65) D’Anna, V.; Daku, L. M. L.; Hagemann, H. Quantitative spectra-structure relations for borohydrides. J. Phys. Chem. C 2015, 119 (38), 21868-21874.

(66) Coates, J. Interpretation of infrared spectra, a practical approach. Encycl. Anal. Chem. 2006, 1, 10815-10837.

(67) Sun, T.; Liu, J.; Jia, Y.; Wang, H.; Sun, D. L.; Zhu, M.; Yao, X. D. Confined $\mathrm{LiBH}_{4}$ : Enabling fast hydrogen release at similar to 100 degrees C. Int. J. Hydrogen Energy 2012, 37 (24), 18920-18926.

(68) Plerdsranoy, P.; Utke, R. Confined $\mathrm{LiBH}_{4}-\mathrm{LiAlH}_{4}$ in nanopores of activated carbon nanofibers. Int. J. Hydrogen Energy 2015, 40 (22), $7083-7092$.

(69) Javadian, P.; Sheppard, D. A.; Buckley, C. E.; Jensen, T. R. Hydrogen storage properties of nanoconfined $\mathrm{LiBH}_{4}-\mathrm{NaBH}_{4}$. Int. J. Hydrogen Energy 2015, 40 (43), 14916-14924.

(70) Laiti, E.; Persson, P.; Ohman, L. O. Balance between surface complexation and surface phase transformation at the alumina/water interface. Langmuir 1998, 14 (4), 825-831.

(71) Hiyoshi, N.; Yogo, K.; Yashima, T. Adsorption characteristics of carbon dioxide on organically functionalized SBA-15. Microporous Mesoporous Mater. 2005, 84 (1-3), 357-365.

(72) Zhao, X. S.; Lu, G. Q. Modification of MCM-41 by surface silylation with trimethylchlorosilane and adsorption study. J. Phys. Chem. B 1998, 102 (9), 1556-1561.

(73) Irvine, J. T. S.; Sinclair, D. C.; West, A. R. Electroceramics: Characterization by impedance spectros-copy. Adv. Mater. 1990, 2, $132-138$.

(74) Verkuijlen, M. H. W.; Ngene, P.; de Kort, D. W.; Barre, C.; Nale, A.; van Eck, E. R. H.; van Bentum, P. J. M.; de Jongh, P. E.; Kentgens, A. P. M. Nanoconfined $\mathrm{LiBH}_{4}$ and enhanced mobility of $\mathrm{Li}^{+}$and $\mathrm{BH}_{4}^{-}$studied by solid-state NMR. J. Phys. Chem. C 2012, 116 (42), 22169-22178.

(75) Epp, V.; Wilkening, M. Fast Li diffusion in crystalline $\mathrm{LiBH}_{4}$ due to reduced dimensionality: Frequency-dependent NMR spectroscopy. Phys. Rev. B: Condens. Matter Mater. Phys. 2010, 82 (2), 020301. 